\title{
Evaluate equivalent-sectional shear modulus for laminated glass beams using in torsion tests and photogrammetry method
}

Kal Uheida

Edinburgh Napier University

\section{Yu Deng}

Guangxi University of Science and Technology

Hexin Zhang ( $\boldsymbol{\nabla}$ j.zhang@napier.ac.uk)

Edinburgh Napier University https://orcid.org/0000-0001-5262-6476

\section{Laura Galuppi}

University of Parma

Jiaxiang Gao

Edinburgh Napier University

Li Xie

Dongguan University of Technology

Shuge Huang

Edinburgh Napier University

\section{Xuanshen Qin}

Guangxi University of Science and Technology

\section{Simon H F Wong}

Technological and Higher Education Institute of Hong Kong

Jianwen Guo

Dongguan University of Technology

\section{Guangxin Zhang}

Guangxi Polytechnic of Construction

\section{Ahmed Mohamed}

Edinburgh Napier University

\section{Research Article}

Keywords: Laminated glass beam, equivalent-sectional shear modulus, Glass beam torsion test, Photogrammetry method for glass structures

Posted Date: August 16th, 2021 
DOI: https://doi.org/10.21203/rs.3.rs-812467/v1

License: (c) (1) This work is licensed under a Creative Commons Attribution 4.0 International License. Read Full License 


\title{
Evaluate equivalent-sectional shear modulus for laminated glass beams using in torsion tests and photogrammetry method
}

\author{
Kal Uheida ${ }^{\mathrm{a}}$, Yu Deng ${ }^{\mathrm{b}}$, Hexin Zhang ${ }^{\mathrm{a},{ }^{*}}$, Laura Galuppi ${ }^{\mathrm{c}}$, Jiaxiang Gao ${ }^{\mathrm{a}}$, Li Xie ${ }^{\mathrm{e}}$, Shuge Huang ${ }^{\mathrm{a}}$, \\ Xuanshen Qin ${ }^{\mathrm{b}}$, Simon H F Wong ${ }^{\mathrm{d}}$, Jianwen Guo ${ }^{\mathrm{e}}$, Guangxin Zhang ${ }^{\mathrm{f}}$, Ahmed Mohamed ${ }^{\mathrm{a}}$

\begin{abstract}
${ }^{a}$ School of Engineering and the Built Environment, Edinburgh Napier University, 10 Colinton Road, Edinburgh, Scotland, UK, EH10 5DT

${ }^{\mathrm{b}}$ School of Civil Engineering and Architecture, Guangxi University of Science and Technology, Liuzhou, China 545006

${ }^{\mathrm{c}}$ Department of Engineering and Architecture, University of Parma, Parco Area delle Scienze 181/A, I-43124 Parma, Italy

${ }^{\mathrm{d}}$ Department of Construction Technology and Engineering, Technological Higher Education Institute of Hong Kong, 20A Tsing Yi Road, Tsing Yi Island, New Territories, Hong Kong

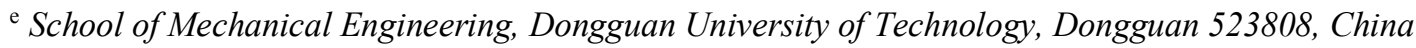

${ }^{\mathrm{f}}$ Department of Civil Engineering, Guangxi Polytechnic of Construction, Nanning, Guangxi, China 530007
\end{abstract}

\begin{abstract}
This paper proposes a concise concept for quantifying the shear/torsional stiffness of the laminated glass beams experimentally by introducing the Equivalent-Sectional Shear Modulus (ESSM), that is directly measured from the torque and sectional-rotation correlation with the torsion test and tailor-made photogrammetry technique. The advantage of this method is originated from the concept of measuring the overall rotation to torque response of a laminated glass beam altogether rather than the component individually. This eliminates the uncertainties of analytical approximations that are commonly adopted by most existing methods in which the composite shear/torsion stiffness is derived from its component
\end{abstract}

\footnotetext{
* Corresponding author

E-mail address: j.zhang@napier.ac.uk (Hexin Zhang)
} 
mechanical properties. The photogrammetry technique increased the accuracy of the sectional rotation measurement by acquiring dense displacement sample points on the glass beam simultaneously. The accuracy of the photogrammetry setup and efficacy of the test design were proven by a micrometre and a monolithic glass beam test. One sample each for the polyvinyl butyral (PVB) and SentryGlas Plus (SGP) laminated glass beams were tested multiple times non-destructively to determine the ESSM. The result of the SGP laminated glass beam showed a closer agreement with the previous studies, however the result of the PVB laminated glass beam exhibited a larger difference from the previous studies. It also suggested that mechanical properties of the interlayer played an important role in the composite behaviour of the laminated glass beam. The experimental outcomes have demonstrated the proposed method is an accurate and effective technique for measuring the ESSM of laminated glass beams.

Keywords: Laminated glass beam; equivalent-sectional shear modulus; Glass beam torsion test; Photogrammetry method for glass structures. 


\section{Introduction}

Structural glass beams are widely used in supporting floor and roof plates, glass walls and other applications due to many favourable characteristics inherent in the material such as high compressive strength, flexibility, aesthetics and sustainability. With the growing demand for greater transparency in structures, structural glass elements such as beams are required to maintain redundancy in a full-load bearing capacity further to traditionally resisting only wind loads. Glass is brittle in nature and ruptures instantaneously with no plastic region of failure thus glass beams are typically of the laminated type, as in the case of a shattered pane fragments adhere to the interlayer and the element will maintain some redundancy post-failure. Understanding the behaviour of such composite structures is significantly different to monolithic elements and poses new challenges in engineering design. Additionally, the absence of a finalised glass design code poses further uncertainty to the engineer and can result in overdesign to meet critical failure criteria.

The cross-section of a glass beam is normally thin and slender. One of the most important design considerations is in the lateral torsional buckling (LTB) phenomena. This has been a hot topic [1] in the field as several recent studies have focused on the LTB mode in glass beams [2-10], and analytical models have been proposed in the pre-normative glass design code [11]. One of the key factors in modelling the structural behaviour of the glass beam in lateral buckling failure is the estimation of the shear modulus, G, which is an important mechanical property when determining the recovery torque in the governing equation of the lateral stability. Theoretically, for monolithic glass, the shear modulus can be determined in relation to two other elastic coefficients - the Young's Modulus $E$ and Poisson's Ratio $v$ assuming a linear-elastic material response. In a multi-ply laminated glass beam modelling the composite effect is particularly challenging, as the interlayer rigidity is many times lower than the glass layers [8]. 
The assessment of the structural response of laminated glass is complicated by the fact that the polymer behaviour is viscoelastic and temperature dependent [12]. In the design practice, the quasi-elastic approximation [13] is usually adopted. This considers the polymer as an elastic material, with a secant stiffness defined according to environmental temperature and characteristic duration of applied load. Based on this approximation, the laminate is a linear elastic composite. The viscoelastic response of the interlayer leads to a relaxation in time of the overall stiffness of laminated glass elements, influencing also their buckling response. In particular, collapse may be achieved after a certain time (see [14] and [15]).

There have been several experimental methods applied that attempt to determine the shear modulus in isotropic materials. The material response for linearly-elastic behaviour can be determined most basically by tensile testing on small material samples. It is less common to test glasses and brittle materials using tensile tests unlike other materials however, as large stresses and strains must be reached to obtain a low uncertainty measurement on the elastic moduli. Compressive tests also must carefully consider the sample geometry to avoid buckling in long samples or barrelling in short samples so these are also uncommon [16]. Additionally, both these types of tests are destructive in nature and highly sensitive to surface defects that easily occur in glass. The three-point beam bending test can achieve significantly higher displacements than tensile tests, however it is only able to determine the Young's Modulus, therefore the shear modulus cannot be acquired [16].

Alternatives to mechanical testing for the shear modulus can be found in ultrasonic and resonance techniques $[17,18]$. The former incorporates sound velocities which produce small measurable displacements, while the latter applies vibrations to the sample which induce elongation, torsion and bending frequencies which can be measured to calculate the shear modulus. The resonance technique has been adopted in the ASTM code C623 - 92 to determine the shear modulus in glasses and ceramics [18]. Both of these methods are non-destructive in 
nature, however they can only produce very miniscule displacements and are limited to the linear-elastic framework and homogeneous materials, thus they are inapplicable to composites such as glass laminates.

Unfortunately, none of the above test methods recreate a similar stress scenario to LTB tests. It is for this reason the torsion test was selected in this study. This creates a more comparable stress scenario to LTB tests and also generates a state of 'pure shear', one of the most ideal conditions to determine the shear modulus. However, it is not as commonly used or well understood as other methods such as bending experiments. A torsion test method for structural-sized slender rectangular beams exists in the timber code BS EN 408:2010 [19], and has been studied by researchers in the area of timber and timber-composite beams $[20,21]$ who have identified shortcomings in the existing procedure and highlighted the inability to obtain the required angular deformation data direct from the torsion machine. Aside from a paneltorsion test method proposed in the draft glass EC [11] which focuses on load-time and temperature effects on the interlayer, there have been no published experimental torsion studies on structural-sized monolithic or laminated glass beams to date.

Measuring displacements in mechanical experiments can be performed fairly accurately using contact-based devices such as inclinometers and linear variable differential transducers (LDVTs), however these have several limitations. The inclinometer is limited to one device per data point and by the base area of the sensor, LDVTs are limited to measure in one dimension, and both devices are contact based so they can be easily damaged during testing and lose measuring accuracy.

Alternatively, it is possible to use a non-contact method such as photogrammetry in this manner, which was originally proposed around the 19th century for topographic mapping [22]. The earliest development of close-range photogrammetry for experimental stress/strain measurements using digital imaging were performed in 1982 [23,24]. Today, through the 
development of sophisticated computer vision software and high spec cameras, it is possible for engineers to extract precise 3D measurements from 2D images in a highly efficient manner. Binocular stereo-vision is a photogrammetric technique that uses a system of two linked cameras which are calibrated in order to obtain various parameters about the cameras and their relation to other objects in view. Photogrammetric techniques have been successfully applied by researchers [20,21,25-28][29] to measure stress-strain deformations in structural timber beams by marking and reading precise target points at required areas of interest on beam samples.

In this paper, the torsional behaviour of monolithic, polyvinyl butyral (PVB) and SentryGlas Plus (SGP) laminated structural glass beams were investigated through nondestructive, structural-sized experimental tests. In order to obtain accurate measurements of torsional stress-strain deformations in each experiment, a non-contact, tailor-made photogrammetry method was applied. Prior to torsion testing, a preliminary experiment was setup and performed to evaluate the measuring accuracy of the employed photogrammetric system against digital micrometre readings. The viability of the test design was proven by the monolithic glass beam torsion test. Four tests were performed on an individual sample and the shear modulus was measured and compared with the theoretical shear modulus for monolithic soda-lime silica glass, which was calculated from the Young's modulus and the Poisson's ratio. For the PVB and SGP laminated glass beams, seven and four torsion tests were performed respectively on one sample of each type. The ESSM of each laminated glass beam was calculated by applying Saint-Venant's torsion theory. The method was then applied to determine the composite ESSM for PVB and SGP laminated glass beams. 


\section{Experimental Procedure}

\subsection{Variables, specimens and equipment}

The experimental procedure was designed to perform structural-sized, non-destructive torsion tests on monolithic, PVB and SGP laminated glass beams in order to evaluate the shear modulus, or the ESSM in these types of beams. To accurately measure the deformation in torqued beam samples, a close-range non-contact photogrammetry method was employed and evaluated in terms of its measuring accuracy. The three different structural glass beam types examined (Table 1) were $2.4 \mathrm{~m}$ long with a length-to-height ratio of 10:1. All beams were (thermally) toughened and have been heat-soaked post manufacture to reduce the risk of nickelsulphide failure during testing [30]. Two pairs of beech wood inserts were used to cushion the glass-steel clamp contacts at both ends the glass beam (Fig. 1). The first sample, MONO1, is a monolithic beam of $10 \mathrm{~mm}$ width (b). The second sample, 2PVB1, is a two-ply laminated beam with a polyvinyl butyral (PVB) interlayer. The third sample, 2SGP1, is a two-ply laminated beam with a SentryGlasPlus (SGP) interlayer. Glass ply's for laminate samples are 10mm each with $1.52 \mathrm{~mm}$ interlayers. Table 2 lists some of the relevant listed material properties for sodalime silica glass [31].

\section{Target marking}

All beam samples were set up with small $5 \mathrm{~mm}$ diameter circular targets as it is simple to accurately extract the centre points of circles. These have been arranged into columns at even distance apart (Fig. 2), and act as points of interest for displacement measurement. To maximise the visibility and readability of targets when extracting the data, a contrasting grey colour value between targets and background was used. White targets on a black background were plotted to strips of adhesive label and stuck to the beam face parallel to each other, with 
$70 \mathrm{~mm}$ horizontal spacing and $15 \mathrm{~mm}$ vertical spacing between each target. Additionally, thin reticules are plotted between targets to aid in the target recognition process. Considering that the adhesive paper may not deform at the same pattern or rate with the glass surface, the paper connecting two adjacent target points in a column line were cut through with a sharp-blade knife to make sure there were separated to avoid the interference of each other during the test. There will usually be a small variation in the spacing between columns from human error due to cutting, measuring and placing. However, the exact measurements are calculated from the images taken in the calibrated binocular stereo-vision system, therefore in a properly calibrated system the real location of each target will be accurate and reliable.

\section{Torsion machine}

The torsion testing machine manufactured by Tinius Olsen outputs roughly $1 \mathrm{kN}-\mathrm{m}$ of pure torsional force (Fig. 3). It is comprised of one fixed end and one free end allowing for rotation. The rig is fixed to a $5.6 \mathrm{~m}$ long heavy steel bench, which allows for adjustments in length at the fixed end. Chuck jaws are situated at each end with open hexagonal connection points from which clamps can be fixated. The clamps and clamp inserts were custom designed for these experiments for the required size of test samples, and were manufactured at the Edinburgh Napier University fabrication and welding laboratories. The clamps were fabricated in steel for strength and stability, whilst a combination of hard beech wood and plastic were used for the inserts to prevent any surface damage from direct steel-to-glass contact. A control PC with Test Navigator software is linked to the torsion machines sensory system to provide the outputs of angle of twist $\left({ }^{\circ}\right)$ at the machines rotating end, and torsional force in $\mathrm{kN}-\mathrm{m}$. 


\section{Illumination}

The goal of illumination is to make important features of the specimen visible and to suppress undesired features, so that they can later be processed in the machine vision software. To do so, consideration must be given to how light interacts with the object [32]. When working with glass samples, glare from lighting is an important consideration and must be limited as much as possible as this can interfere with the visibility when inspecting points of interest. Setting optimal lighting conditions is therefore of high importance for test images. As standard lights or lamps will reflect to a high degree, a soft box lighting kit was set up to illuminate the test area without causing excessive glare. Additionally, a polarising lens filter was fitted to each camera as there can still be some moderate glare on the test samples causing some difficulty in inspecting points of interest, even with the soft box lights. Furthermore, the direction from which specimens are illuminated must be considered in the setup, as this will continually alter as the specimen rotates under torsion.

\subsection{Binocular stereo-vision system}

Although it is possible to obtain very accurate measurements using a single calibrated camera and image, these measurements are only provided in $2 \mathrm{D}$ and therefore without the disparity $Z$ coordinate the $3 \mathrm{D}$ geometry of the objects surface cannot be reconstructed. The binocular stereo-vision system consists of two cameras looking at the same object, or point of interest. If the interior orientations and the relative orientation of the two cameras are known, the derivation of $3 \mathrm{D}$ surface information of the object can be reconstructed from the images of the two cameras, without the need for any physical measuring.

The primary components of the setup are the cameras and their lenses. In this case due to the low data processing load from the images an inexpensive setup can be comfortably used. Two linked Canon EOS 70D cameras with $50 \mathrm{~mm}$ Canon EF f/1.8 II fixed focal lenses were 
used, with the two-camera setup defining the system as 'binocular' stereo. Cameras were fixed to the left and right of a tripod and linked using a splitter and shutter. A third camera and tripod were set up and additionally linked to the system to acquire data images from the Test Navigator software on the control PC's monitor. This allows the torsion machine data (end rotation, torsional force) to be matched with each stereo image pair.

\section{Pinhole model}

The reconstruction of a 3D scene from 2D images that is taken by cameras with optical lenses is mathematically described by the pinhole model[32], which is based on perspective projection. The camera lens is represented by its optical centre, which corresponds to a point between the 3D scene and 2D image plane and the optical axis which is perpendicular to the plane defined by the lens and passes through the optical centre. The image, camera and world coordinate systems (ICS; CCS; WCS ) are presented in Fig. 4. The camera coordinate system at the lens is at distance of the focal length $f$ to the image coordinate system at the image plane, which is at the sensor. The world coordinate system is set to match the camera coordinate system of the left camera, which makes it possible to determine the spatial position of the right camera in relation to the left. Lens distortions (Fig. 5) can cause the 3D world point $P$ not to lie on a straight line through the projection centre, which are fixed by calibration.

\section{Calibration}

To obtain the world coordinates of a point in a stereo-image pair to perform accurate measurements the system must first be calibrated. The purpose of the calibration is to determine the internal and external camera parameters and correct lens distortions [32]. The internal 
parameters describe the internal geometry and optical characteristics of the camera, such as the focus, lens distortion coefficient and the distance between cells in the sensor. The external, or pose parameters describe the position and orientation of the cameras relative to a world coordinate system and are therefore essential to apply the triangulation-based approach to reconstruct the $3 \mathrm{D}$ scene [32].

In order to calibrate the stereo-vision system, the location of 3D points in the world coordinate system must be known and related to their image projection. The calibration in this work was performed by taking multiple image pairs of a highly-accurate, $160 \times 120 \mathrm{~mm}$ ceramic planar calibration plate supplied by MvTEC with exactly known dimension and colour properties. Several poses were used to acquire an accurate calibration. A data file with full dimensional properties corresponding to the calibration plate was read within the computer vision software HALCON. In order to locate the plate within the program the entire rectangular target area must be visible in both images per stereo image pair. In the 3D setup of the binocular stereo-vision system, Object point $P$ is any point on the calibration plate during the calibration process. Once the calibration process is complete, the setup must not be moved otherwise coordinate data for targets are not relatable to the calibrated system and will thus be invalidated. In the calibration method employed, images of the calibration plate were taken in six different orientations at six different positions around the target area of the beam (36 stereo-image pair's total), as although around 10 poses are usually sufficient for accurate calibration, the authors used a larger number of poses to overcompensate for any cases where some images may be unreadable.

The following optimisation problem for multi-image calibration must be solved to calibrate the stereo system [32]: 


$$
d(\theta)=\sum_{l=1}^{2} \sum_{k=1}^{n_{0}} \sum_{j=1}^{n_{m}} v_{j, k, l}\left\|\boldsymbol{\pi}_{r}\left(\boldsymbol{m}_{j, k, l}, \boldsymbol{\theta}_{r, l}\right)-\boldsymbol{\pi}_{i}\left(\boldsymbol{M}_{j}, \boldsymbol{\theta}_{i, l}\right)\right\|^{2} \rightarrow \min .
$$

Where $n_{\mathrm{m}}$ is the number of calibration marks. $n_{\mathrm{o}}$ is the total images used for calibration. $\boldsymbol{M}_{j}$ denotes the positions of the calibration marks, $\boldsymbol{m}_{j, k, l}$ denotes the projection of the centres of the marks in the first set of calibration images and $\boldsymbol{m}_{j, 2}$ denotes the second set. The vector $\boldsymbol{\theta}$ denotes the camera parameters including the interior orientations of the first and second cameras, the exterior rotations of $n_{0}$ calibration targets in the second image. $\pi i$ denotes the projection of a calibration mark into the ICS, $\boldsymbol{\theta}_{i, l}$ are the subset of camera parameters that influence this projection for the left camera, $\boldsymbol{\pi}_{r}$ denotes the rectification of an image point into the image plane coordinate system, $\boldsymbol{\theta}_{r, l}$ are the subset of camera parameters that influence this rectification for left camera, and $v_{j, k, l}$ is a variable that is 1 if the calibration mark $\boldsymbol{M}_{j}$ is visible in image $k$ of left camera [32]. A calibration image pair with the plate at a left-tilted pose is displayed in Fig. 6.

\section{Stereo reconstruction}

The 3D scene reconstruction can be performed once the camera and pose parameters have been determined through calibration. Before reconstruction the stereo-image pairs must be rectified, meaning that the conjugate points are projected to one common plane which corresponds in parallel to the baseline in Fig. 4. This can be viewed as acquiring stereo-image pairs with a virtual camera system where optical centres and focal lengths are the same as in the real system, however the orientation of the cameras are rotated so they are looking parallel and with collinear $\mathrm{x}$-axes so both image planes are correspondent. 
Firstly, the spatial and positional relationship between both cameras in the binocularstereo system can be expressed through the following rigid transformation [32]:

$$
P_{C_{\text {left }}}=R_{r} P_{C_{\text {right }}}+T_{r}
$$

Where $P_{C_{l e f t}}$ is the coordinate of the left camera. $P_{C_{\text {right }}}$ is the coordinate of the right camera. $R_{r}$ is the rotation matrix and $T_{r}$ is the translation vector. Then the reconstruction of $3 \mathrm{D}$ points is determined from the epipolar geometry as depicted in Fig. 4. Corresponding points $P_{L}$ and $P_{R}$ are projects of world point $P$, epipoles $e_{L}$ and $e_{R}$ also intersect with the image plane to form epipolar lines of intersection, and optical centres $O_{L}$ and $O_{R}$ have their lines of sight projected to form the epipolar plane. Then the known epipolar geometry allows corresponding features to be reduced to one dimension. The rectification of image pairs to the common epipolar geometry is then expressed by [33]:

$$
X_{L}=f \frac{X}{Z}
$$

$$
Z=\frac{b f}{\left(X_{L}-X_{R}\right)}=\frac{b f}{d}
$$

Where $f$ is the focal length, $d$ is the disparity between the two image locations of the conjugate points and $b$ is the baseline as shown in Fig. 4.

\subsection{Target recognition and extraction in HALCON}

The processing and extraction of data for these experiments were performed using MVTec's HALCON software and the in-built development tool HDevelop, which includes an 
integrated database of operators for many machine-vision functions and therefore tailor-made algorithms can be developed in a time-effective manner. The circular targets that were set to the test specimens were first recognised using machine vision techniques based on specific features such as shape, size and colour (grey) value as shown in Fig. 7.

\section{Grey value segmentation}

A global threshold algorithm was applied to segment the image based on the pixels' grey colour value. The threshold operation selects all points in the region of interest (ROI) $R$, which is the part or all of the image selected for processing that lie within a specified range of grey values $g$ and outputs these into a new region $S$. This is defined by [32]:

$S=\left\{(r, c)^{T} \in R \mid g_{\min } \leq f_{r, c} \leq g_{\max }\right\}$

Where $r$ and $c$ are the row and column numbers of a pixel in region $R$. The default values of $g_{\min }=128$ and $g_{\max }=255$ were sufficient to segment the targets in the images assessed for this study and therefore have been applied. In cases where recognition is more difficult this can be modified by checking the grey value histogram for each image in the software. In cases where there are large random fluctuations in the grey value histogram a smoothing filter operation can be applied. As the previous segmentation algorithm returns one region for the result, the individual components of the region separated by grey value, which are the targets, must be computed as connected components by defining pixels with commonalities. 


\section{Target extraction}

To remove unwanted features from the image in order to accurately extract only the targets, some further filtering algorithms were applied based on the characteristics of target size and shape. The area $a$ is the simplest region to be filtered and is defined as [32]:

$$
a=|R|=\sum_{(r, c)^{T} \in R} 1=\sum_{i=1}^{n}\left(c e_{i}-c s_{i}+1\right)
$$

Where $c s_{\mathrm{i}}$ and $c e_{\mathrm{i}}$ are the start and end pixel's column number of the $i^{\text {th }}$ run of a region extracted. Therefore, the area $a$ is simply the number of point's $|R|$ in the region. Additionally, the circular shape of the targets were computed using the circularity algorithm [33]:

$$
C^{\prime}=\frac{F}{\left(\pi \max ^{2}\right)}, \quad C=\min \left(1, C^{\prime}\right)
$$

Where the shape factor $C$ of a perfect circle is $1.0, F$ is the area of the region and max is the maximum distance from the centre to all contour pixels. Then the centre point of each target was calculated as the mean value of the line or column coordinates respectively of all pixels in the region, which is the area of each target. The targets were also sorted chronologically into tuples in order of top-to-bottom, left-to-right.

\subsection{Accuracy experiment}

In order to validate the measuring accuracy of a calibrated stereo-vision system the measurement uncertainty can be evaluated by simple experimentation using a trusted and accurate existing device. Therefore, in this study a digital micrometre measurement test method was developed and performed using the calibrated system. 
This micrometre measurement test was designed to investigate the error between the dial reading and the calculated distance using the stereo-vision system. Two target marks were set to two points on the micrometre, one target at a fixed position on the left end next to the anvil which remains stationery, while the second target was fixed to the spindle and moves laterally with any change in distance on the micrometre. The dial was set to zero and a reference image pair was taken. The dial was then moved along an interval by a spindle turn and the next image pair was taken (Fig. 8). This process was repeated four-to-five times. The world coordinates for the centres of each target were computed using the aforementioned methods in section 2.2. The distance between two targets was then calculated using the following equation of 3D geometry:

Distance $=\sqrt{\left(X_{1}-X_{2}\right)^{2}+\left(Y_{1}-Y_{2}\right)^{2}+\left(Z_{1}-Z_{2}\right)^{2}}$

Where $\mathrm{X} 1, \mathrm{Y} 1, \mathrm{Z} 1$ and $\mathrm{X} 2, \mathrm{Y} 2, \mathrm{Z} 2$ are the world coordinates of the two exacted target points. The relative displacement between targets was calculated from the difference between the calculated distances at each interval. The error percentage between the stereo-vision system and the micrometre dial reading was then calculated by:

$\operatorname{Error} \%=\frac{D_{\text {stereo }}-D_{\text {mic }}}{D_{\text {mic }}} \cdot 100$

Where $D_{\text {stereo }}$ is the distance measured by the stereo-vision system and $D_{\text {mic }}$ is the distance measured by the micrometre dial. 


\subsection{Torsion test}

As there is yet to be evidence of any standardised torsion test procedure for structural glass beams, this torsion test method has been developed by accounting for the material characteristics and behaviour of glass and laminated glass slender rectangular beams, and previous beam torsion experiments on other beam types such as timber [19-21].

Initial parameters such as the cross-sectional dimensions of the beam and the load-rate were set, which was to the machines default of $4^{\circ}$ per minute. The temperature in the test facility is kept constant at $\sim 20^{\circ} \mathrm{c}$ which was checked by thermometer. Firstly, each test sample was preloaded to $\mathrm{a} \sim 5^{\circ}$ angle, as generally when clamping the beam some residual compressive stresses can build up at points of fixation and have some effect on the accuracy of results. Additionally, there may be a small amount of 'jump' in the rotation mechanism at the point of initiation. Concluding the preload, the test was paused, the torque angle and force were reset to zero and a reference image pair is taken.

The torsion test (Fig. 9) was then performed at the specified load-rate and stereo-image pairs were taken at consistent intervals. The third linked camera also simultaneously captured the image of the Test Navigator display on the control PC to relate the angle of twist and torsional force data to each stereo-image pair. The intervals for each sample were varied as laminated samples, particularly SGP, have higher torsional stiffness so are more resistant to torsional force, therefore larger intervals will result in a low number of data intervals. The rate of loading against time for different types of beams are shown in Fig. 10. The tests were performed close to the machines output capacity of $1 \mathrm{kN}-\mathrm{m}$. To conclude each test, the loading was ceased and the final images were taken before returning the machine to zero degrees. 


\subsection{ESSM method}

Saint-Venant's theory for the torsion of slender rectangular cross-sectioned elements has been applied to determine the value of ESSM of the rectangular sections of the specimen tested in this study. Each rectangular section has been designated as the section between two target columns, referred to as $C_{i}$ (any column) and $C_{i+1}$ (adjacent column). The following equations based on Saint-Venants theory are applied to determine $G_{E S S M}$ [34]. Firstly, the twist rate, i.e. angular rotation per unit length, $\beta$, is calculated by:

$$
\beta=\frac{T}{G J}
$$

Where $T$ is the torque applied, and the Saint-Venant's torsional constant, $J$, is:

$$
J=\frac{1}{3} h t^{3}\left[1-\frac{192}{\pi^{5}}\left(\frac{t}{h}\right) \sum_{n=1,3,5, \ldots}^{\infty} \frac{1}{n^{5}} \tanh \frac{n \pi h}{2 t}\right]
$$

Considering the dimensional properties of beam samples in Table 1, for the considered glass beam samples eq. (11) provides

$$
J= \begin{cases}0.3246 h t^{3} & \text { for monolithic glass beams } \\ 0.3145 h\left(t_{1}+t_{2}+t_{\text {int }}\right)^{3} & \text { for laminated glass beams }\end{cases}
$$

Where $t_{1}, t_{2}$ are thicknesses of their respective glass layers, and $t_{\text {int }}$ is the thickness of the interlayer. Although the thickness of the sample laminated glass beams is of the order of 10-20 mm, while the width of the structural panes (beams and fins) is usually higher than 200 
$\mathrm{mm}$, the classical approximate solution for the elastic torsion of thin prisms with narrow rectangular section [35] can be used, according to which eq. (11) can be approximated as

$$
J=\frac{1}{3} h t^{3}
$$

It is worthy to mention that caution should be taken as a perceptible difference can be noticed if this approximation is adopted.

Therefore, to determine $G_{E S S M}$, eq. (10) can be extended to:

$$
G_{E S S M}=\frac{T}{J \beta}
$$

By applying 3D geometry to the coordinates of target columns $C_{i}$ and $C_{i+1}$, their spatial relationship to each other was determined and thus the angular rotation $\theta$ per section. In standard mathematics a plane in $3 \mathrm{D}$ space, which is determined by the coordinates of all targets and represents the flat target area at reference $0^{\circ}$ of twist, can be expressed from three points by:

$$
a_{1} x+b_{1} y+c_{1} z+d_{1}=0
$$

The method of least squares, a standard approach was employed to fit the 3D plane from the coordinates of the165 target points at initial status after pre-load. The parameter of eq. (15): $a_{1}$, $b_{1}, c_{1}$ and $d_{1}$ are obtained from this step. 
Each line of target column in 3D space, which are determined by the coordinates of each target column, are described by:

$\frac{x-x_{0}}{a_{2}}=\frac{y-y_{0}}{b_{2}}=\frac{z-z_{0}}{c_{2}}$

Again, the method of least squares was employed to fit the 3D representative line of each target column at different loading stages, from which the parameter of $x_{0}, y_{0}, z_{0}, a_{2}, b_{2}$ and $c_{2}$ are obtained. Consider above two steps are all standard approach in linear algebra, and also for sake of brevity, the definitions of the parameters are not specified one by one.

The angle $\theta C_{i}$ between the $i^{\text {th }}$ target column line $C_{i}$ and the refence plane (Fig. 11) can be determined by applying the following equation:

$$
\sin \left(\theta C_{i}\right)=\frac{a_{1} a_{2}+b_{1} b_{2}+c_{1} c_{2}}{\sqrt{\left(a_{1}^{2}+b_{1}^{2}+c_{1}^{2}\right)\left(a_{2}^{2}+b_{2}^{2}+c_{2}^{2}\right)}}
$$

The twist rate $\beta_{i}$ of the $i^{\text {th }}$ target column line to the neighbouring target column lines $(i+1)^{\text {th }}$ can be obtained from

$$
\beta_{i}=\frac{\theta C_{i+1}-\theta C_{i}}{l}
$$

Where $l$ is the distance between the $i^{\text {th }}$ and $(i+1)^{\text {th }}$ target column lines. The average twist rate of the target region $\bar{\beta}$ can be computed from

$$
\bar{\beta}=\frac{\sum \beta_{i}}{n}
$$


The average ESSM are calculated using the average twist rate of the target region.

\section{Results and discussion}

\subsection{Validation of photogrammetry and torsion test method}

Accuracy validation was performed in two stages. Firstly, at the instrumentation level, the measuring accuracy of the calibrated photogrammetric stereo-vision system was evaluated against an alternative reliable measuring device - the digital micrometre. This test proves the calibration process as shown in Fig. 12 has been conducted properly and the photogrammetry setup at that moment provided the required accuracy for measuring the displacements of the target points attached on the surface of the glass beams. Once the calibration and the micrometre validation as shown in Fig. 13 have been performed, the two cameras should be kept untouched until all tests completed. Once the cameras have been moved, the test setup must re-calibrate, and the micrometre validation should be conducted again to confirm the accuracy. A typical test result for the micrometre validations are displayed in Table 3 . The displacement of target points on the micrometre ranged from around $3 \mathrm{~mm}$ to $10 \mathrm{~mm}$ - the typical displacement range of target points on the glass beam under torsion. A very high accuracy against micrometre dial readings was observed, with only $0.02 \%-0.33 \%$ error between the two measuring systems. Therefore, a properly calibrated binocular stereo-vision system was confirmed and, furthermore, the use of small circular targets was found to be an accurate and reliable means to perform the displacement track-and-measure task.

Secondly, at structural member level, the monolithic soda-lime silica glass beam sample was used to examine the viability of the test design. As glass is an isotropic material, the theoretical shear modulus can be calculated from its Young's modulus and the Poisson's ratio 
detailed in Table 2, i.e., $G=\frac{E}{2(1+v)}$, so that $G=28.455 \mathrm{GPa}$. The theoretical value was then compared with the ESSM value that was computed from the torque-displacement results measured using the proposed photogrammetry method. The test results are shown in Fig. 14, from which the ESSM value can be determined. The $G_{E S S M}=\frac{T}{J \theta}$, so that the $G_{E S S M}=$ 28.187 GPa. The ESSM value agreed well with the theoretical shear modulus. This proved that the proposed torsion test and photogrammetry method was an accurate method for measuring the shear modulus of the monolithic or laminated glass beam structures in the next step.

After these two stage validations, the PVB and SGP laminated glass beam samples were then tested with the torsion test method detailed in the Section 2.5. The ESSM values were calculated from the torque-rotation relationships captured by the proposed photogrammetry method detailed in this paper. The ESSM results were compared with results calculated by an analytical approach proposed by Amadio and Bedon [10], and the Enhanced Effective Thickness method for torsion proposed by Galuppi and Royer-Carfagni [8], the details of which are presented in the following section.

\subsection{Shear modulus of laminated glass beams}

Three different approaches are suggested by the literature for the analytical evaluation of the effective torsional stiffness of laminated glass beams. The first one is proposed by Kasper et al. [36], that applies to laminates composed of two or three glass plies, all with the same thickness.

Another approach proposed Amadio and Bedon [10] and validated by Luible and Crisinel [9], allows to determine the torsional stiffness of laminated glass beams composed of two glass plies only by using sandwich theory to account for the composite action between glass and interlayers. 
Considering the equivalent torsional stiffness in the model:

$G J_{e f f ; A-B}=G\left(J_{\text {glass } 1}+J_{\text {glass } 2}+J_{\text {comp }}\right)$.

Where $G$ is the shear modulus of glass, $J_{\text {glassi }}=\frac{h t_{i}^{3}}{3}$ is the torsional constant of the $i$-th glass layer, evaluated by means of eq. $(13)^{\dagger}$, and suffix A-B refers to the Amadio-Bedon model [10]. The torsional constant due to composite action of the interlayer $J_{\text {comp }}$ is given by

$J_{\text {comp }}=J_{s}\left(1-\frac{\tanh \frac{\lambda h}{2}}{\frac{\lambda h}{2}}\right)$.

$J_{s}=4\left(\frac{t_{1}+t_{2}}{2}+t_{I N T}\right)^{2} \frac{t_{1} t_{2}}{t_{1}+t_{2}} h ; \quad \lambda=\sqrt{\frac{G_{I N T}}{G} \frac{t_{1}+t_{2}}{t_{I N T} t_{1} t_{2}}}$.

The theoretical values for $G_{I N T}$ can be determined by calculation of the elastic property relationship, where the relevant $E$ and $v$ values for PVB and SGP exist in the available data [37]. These can also been verified by the results of [6] where experimental LTB studies were performed.

Once the torsional stiffness is calculated with (23), the equivalent shear modulus $G_{E S S M}$ , i.e. the homogenised value across the entire section, may be evaluated by requiring that

$G J_{\text {eff } ; A B}=G_{E S S M} J_{\text {homog }}$

\footnotetext{
${ }^{\dagger}$ Notice that a more accurate evaluation of the torsional stiffness of the individual glass panes should be made by adopting eq. (11). However, both the approach proposed in [8,9] and the EET model of [7] are based on the assumption of $t<h$, and hence the simplified formula for the elastic torsion of thin prisms with narrow rectangular section is used.
} 
Where $J_{\text {homog }}$ is the torsional constant of the homogenized section, evaluated by means of Eq. (11) (or (13)), by considering the laminated glass dimensions recorded in Table 1.

The third analytical model proposed by the literature is the Enhanced Effective Thickness (EET) for laminated glass beams and plates under torsion [8]. This is a very general method, allowing to evaluate the torsional response of laminated rectangular panes composed by an arbitrary number of glass plies of arbitrary thickness. According to this approach, the equivalent torsional stiffness may be evaluated as $G_{g} K_{e f f ; E T}$, where, with the same notation of (20) and (23),

$\frac{1}{J_{e f f ; E E T}}=\frac{\eta}{J_{m}}+\frac{1-\eta}{J_{g l a s s 1}+J_{g l a s s} 2}$

where $J_{m}=J_{\text {glass } 1}+J_{\text {glass } 2}+J_{s}$, with $J_{s}$ given by eq. (22), is the torsion constant of an ideal beam cross section composed by the glass parts properly spaced of the interlayer thickness, rather than a full-glass section [7]. It may be verified that that this is almost coincident with the torsion constant of a beam with thickness $\left(t_{1}+t_{2}+t_{\text {int }}\right)$.

The non-dimensional shear coupling parameter $\eta$ tunes the behaviour from the so-called layered limit with frictionless sliding glass plies $(\eta=0)$ to the monolithic limit $(\eta=1)$, where the tangential stiffness of the polymer provides the complete shear-coupling of the glass plies. Notice that this depends not only on the beam width, but also on its length, because the EET model for torsion covers both the $1 \mathrm{D}$ beam and the 2D plate-geometries. The shear coupling parameter may be calculated as

$$
\eta=\frac{1}{1+12 \frac{t_{I N T} t_{1} t_{2}}{t_{1}+t_{2}} \frac{J_{\text {glass } 1}+J_{\text {glass } 2}}{J_{m}} \frac{G}{G_{I N T}} \frac{L^{2}+h^{2}}{L^{2} h^{2}}}
$$


Once the torsional stiffness is calculated with (24), the equivalent shear modulus $G_{E S S M}$ may be evaluated with a formula analogue to (22).

\section{PVB Sample}

A total of seven experiments were performed on the two-layer PVB laminate beam sample. Errors were identified in acquiring the coordinate data in the fourth test and in the calibration of the sixth test so these were disregarded from the results. This may be due to the camera(s) being accidentally moved after the calibration. From the remaining test datum, the ESSM value for the two-layer PVB laminated glass beam was computed, $G_{E S S M}=7.19 \mathrm{GPa}$ with results again closely adhering to the linear regression of $R^{2}=0.9976$ (Fig. 14). By performing the calculation by the methods detailed by in the previous section [10] and [8] based on sandwich theory and effective thickness approximation, respectively. The shear module of $G_{I N T}$ is a time-dependent mechanical theory as descripted in Table 4 provided by the manufacturer of the interlayer. The total testing duration is around 10 minutes including the preload period as detailed in Fig. 10. The $G_{I N T}$ can be calculated by interpolation using the data in Table 4, and it is equal to $1.518 \mathrm{MPa}$. For the shear modulus of glass, the theoretical value $G=28.455 \mathrm{GPa}$ has been used.

After performing the analysis, the theoretical shear modulus are

$G=6.448 \mathrm{GPa} \quad$ for the Amadio-Bedon (A-B) method (10.33\% difference to ESSM test result: $7.19 \mathrm{GPa})$;

$G=6.445 \mathrm{GPa} \quad$ for the Enhanced Effective Thickness method (10.36\% difference to ESSM test result: $7.19 \mathrm{GPa})$. 
These results are quite lower than that obtained experimentally. The discrepancy may be explained by considering that, to use the Amadio-Bedon and the EET methods, the approximation of narrow rectangular cross section, on which the methods are based, has been used to evaluate the torsion constant of the individual glass plies. This means that they have been calculated by using the simplified expression (13) instead of (12).

Remarkably, it may be verified that the accuracy of the analytical results may be increased by using, instead, expression (11-12), even if this is not rigorous in the framework of the A-B and the EET methods. In this case, the theoretical shear modulus are

$G=6.674 \mathrm{GPa} \quad$ for the A-B method (7.18\% difference to ESSM test result: $7.19 \mathrm{GPa})$; $G=6.672 \mathrm{Gpa} \quad$ for the Enhanced Effective Thickness method (7.21\% difference to ESSM test result: $7.19 \mathrm{Gpa})$.

which agrees closely to the experimental results obtained in this paper. More detailed calculations are included in the Appendix.

As observed in [8], the results obtained with the two approaches are very close on to each other for low values of the interlayer shear modulus.

\section{SGP Sample}

A total of four experiments were performed on the two-layer SGP laminated glass beam sample. In the fourth test a mechanical failure occurred within the clamp inserts, so this experiment was disregarded. From the successful experiments, the calculation of the ESSM determined the value of $G_{E S S M}=23.68 \mathrm{GPa}$ with linear regression adherence $R^{2}=0.9935$ (Fig. 14). In order to calculate the shear modulus using the A-B and EET method, the $G_{I N T}$ for SGP can be calculated using the interpolation with the data listed in Table 5 provided by the 
manufacturer of the interlayer, i.e., $G_{I N T}=191.03 \mathrm{MPa}$. Based on the method detailed in Section 3.2, the shear modulus of the two-layer SGP laminated glass beam has been calculated, by adopting eq. the approximated expression (13) for the torsion constant of glass plies, as

$G=22.081 \mathrm{GPa} \quad$ for the A-B method $(6.75 \%$ difference to ESSM test result: $23.68 \mathrm{GPa})$; $G=24.071 \mathrm{GPa} \quad$ for the EET method (1.65\% difference to ESSM test result: $23.68 \mathrm{GPa})$.

By considering, instead, eq. (11), the following results can be obtained:

$G=23.244 \mathrm{GPa} \quad$ for the A-B method (1.84\% difference to ESSM test result: $23.68 \mathrm{GPa})$; $G=25.354 \mathrm{GPa} \quad$ for the EET method (7.07\% difference to ESSM test result: $23.68 \mathrm{GPa})$.

Notice that, in the former case the EET model is in better agreement with experimental results, while in the latter case the A-B model provides better results. This result revealed that the shear stiffness of the interlayer has a considerable impact to the overall composite effect of the laminated glass beam.

As observed in [8], for high values of the interlayer shear modulus, the torsional stiffness obtained with the EET approach is in general overestimates with respect to the A-B model.

This study also revealed that measuring the structural torsional response and computing against the applied torque was a direct, effective and accurate method of evaluating the composite shear/torsional stiffness of laminated glass beams. The shear modulus is an important mechanical property that directly affects the critical load estimated by various analytical model including lateral torsional buckling. The ESSM method provided not only a reliable way for validating the existing or new analytical models for estimating the overall 
shear/torsional stiffness from the component mechanical properties but also a set of target data for the other researchers to fine tune their models.

\section{Conclusions}

- A novel concept was proposed the first time for quantifying the torsional stiffness of the laminated glass beams experimentally by introducing equivalent-sectional shear modulus (ESSM) that directly measured from the torque and sectional-rotation correlation with the torsion test and tailor-maid photogrammetry technique.

- The accuracy of the instrumentation and the test setup was validated by a micrometre test. The test setup was proven to be highly accurate.

- The efficacy of the test design was examined by the torsion tests on the monolithic structural glass beam, the ESSM value calculated from experimental results agreed well to the theoretical shear modulus value.

- Seven PVB laminated glass beam tests were performed, and the ESSM was determined. The test result of the PVB laminated glass beam has suggested a range of $7-10 \%$ difference from results calculated by the analytical model proposed in a previous study.

- Four SGP laminated glass beam tests were performed, and the ESSM was determined. Experimental results agreed better with the results calculated by existing analytical models. It suggested that the variation of the interlay shear stiffness has a considerable impact to the overall composite shear/torsional stiffness.

- The proposed method is a direct, effective and accurate method of evaluating the composite shear/torsional stiffness of the laminated glass beam and provided a reliable experimental approach to validate the existing or new analytical models for estimating the overall shear stiffness of the laminated glass beams from the component mechanical properties. 
- Further development of the present work will possibly include the study of multilayered laminated glass beam. Remarkably, the EET is the only analytical model that allows to evaluate the torsional stiffness for this general case.

- Another issue that will be interesting to experimentally investigate is the long-term response of laminated glass beam, subjected to a constant torsion loading. Indeed, due to the viscoelastic properties of the polymer, a time-dependent relaxation is expected.

\section{Acknowledgements}

The authors would like to express their special gratitude to the financial support of the Royal Academy of Engineering - Industrial Fellowship (IF\192023), Royal Academy of Engineering-Visiting Professor (VP2021\7\12), British Council and Ministry of Education, China (UK-China-BRI Countries Education Partnership Initiative 2019), Scottish Funding Council-Innovation Voucher: Bamboo-Timber Composite Materials for Structural Use, Lawrence Ho Research fund, National Nature Science Foundation of China (51768008), China Postdoctoral Science Foundation Project (2017M613273XB), Liuzhou Scientific Research and Technology Development Plan (2017BC40202) and Nature Science Foundation of Guangxi Zhuang Autonomous Region (2019JJA160137). The authors also acknowledge the support of Innovation Team Support Plan of Guangxi University of Science and Technology.

\section{Conflict of interests}

The author declares no conflict of interest. 


\section{Appendix}

The equivalent sectional shear modulus for laminated glass beams with two glass layers is elucidated by applying sandwich theory (A-B method [10]), eq. (11) was used in this demonstration:

$G_{E S S M}=\frac{G\left(J_{\text {glass } 1}+J_{\text {glass } 2}+J_{\text {comp }}\right)}{J_{\text {homog }}}$

The shear modulus of glass $G$ is expounded in Section 3.1

$G=\frac{E}{2(1+\mu)}=\frac{7 \times 10^{10}}{2(1+0.23)}=28.455 G P a$

The torsional constants for glass layers and laminated glass beams are demonstrated in Section 2.6

$J_{\text {glass } 1}=J_{\text {glass } 2}=0.3246 h t^{3}=0.3246 \times 240 \times 10^{3}=7.7904 \times 10^{4} \mathrm{~mm}^{4}$

$J_{\text {homog }}=0.3145 h\left(t_{1}+t_{I N T}+t_{2}\right)^{3}=0.3145 \times 240 \times(10+1.52+10)^{3}$

$$
=7.5224 \times 10^{5} \mathrm{~mm}^{4}
$$

The torsional constants due to composite action of interlayers are obtained as

$$
\begin{gathered}
J_{S}=4\left(\frac{t_{1}+t_{2}}{2}+t_{I N T}\right)^{2} \frac{t_{1} t_{2}}{t_{1}+t_{2}} b=4 \times\left(\frac{10+10}{2}+1.52\right)^{2} \times \frac{10^{2}}{10+10} \times 240 \\
=6.3701 \times 10^{5} \mathrm{~mm}^{4}
\end{gathered}
$$

The shear moduli with 10 mins load duration and $20{ }^{\circ} \mathrm{C}$ temperature of PVB and SGP may be calculated to be 1.52 and $191.03 \mathrm{MPa}$ by applying linear interpolation to the material properties data from DuPont. Hence, the analytical ESSM values for PVB and SGP laminated glass are respectively evaluated as follows:

$\lambda=\sqrt{\frac{G_{P V B}}{G} \frac{t_{1}+t_{2}}{t_{P V B} t_{1} t_{2}}}=\sqrt{\frac{1.52 \times 10^{6}}{28.455 \times 10^{9}} \frac{10+10}{1.52 \times 10^{2}}}=0.00265 \mathrm{~mm}^{-1}$ 


$$
\begin{aligned}
& J_{\text {comp }}=J_{s}\left[1-\frac{\tanh \frac{\lambda h}{2}}{\frac{\lambda h}{2}}\right]=6.3701 \times 10^{5}\left[1-\frac{\tanh \frac{0.00265 \times 240}{2}}{\frac{0.00265 \times 240}{2}}\right] \\
& =2.0629 \times 10^{4} \mathrm{~mm}^{4} \\
& G_{E S S M_{\_} P V B}=\frac{G\left(J_{\text {glass } 1}+J_{\text {glass } 2}+J_{\text {comp }}\right)}{J_{\text {homog }}}=\frac{28.455 \times(7.7904+7.7904+2.0629) \times 10^{4}}{7.5224 \times 10^{5}} \\
& =6.674 G P a \\
& \lambda=\sqrt{\frac{G_{S G P}}{G} \frac{t_{1}+t_{2}}{t_{S G P} t_{1} t_{2}}}=\sqrt{\frac{191.03 \times 10^{6}}{28.455 \times 10^{9}} \frac{10+10}{1.52 \times 10^{2}}}=0.0297 \mathrm{~mm}^{-1} \\
& J_{\text {comp }}=J_{s}\left[1-\frac{\tanh \frac{\lambda h}{2}}{\frac{\lambda h}{2}}\right]=6.3701 \times 10^{5}\left[1-\frac{\tanh \frac{0.0297 \times 240}{2}}{\frac{0.0297 \times 240}{2}}\right]=4.5869 \times 10^{5} \mathrm{~mm}^{4} \\
& G_{E S S M \_S G P}=\frac{G\left(J_{\text {glass } 1}+J_{\text {glass } 2}+J_{\text {comp }}\right)}{J_{\text {homog }}}=\frac{28.455 \times(7.7904+7.7904+45.869) \times 10^{4}}{7.5224 \times 10^{5}} \\
& =23.244 G P a
\end{aligned}
$$

As discussed in Section 3.2, the ESSM values may also be evaluated by using EET model.

Detailed determination of them is presented as follows:

$$
\begin{aligned}
& J_{m}=J_{\text {glass } 1}+J_{\text {glass } 2}+J_{s}=2 \times 7.7904 \times 10^{4}+6.3701 \times 10^{5}=7.9282 \times 10^{5} \mathrm{~mm}^{4} \\
& \eta=\frac{1}{1+12 \frac{t_{\text {INT }} t_{1} t_{2}}{t_{1}+t_{2}} \frac{J_{\text {glass } 1}+J_{\text {glass } 2}}{J_{m}} \frac{G}{G_{P V B}} \frac{L^{2}+h^{2}}{L^{2} h^{2}}} \\
& =\frac{1}{1+12 \frac{1.52 \times 10^{2}}{10+10} \frac{(7.7904+7.7904) \times 10^{4}}{7.9282 \times 10^{5}} \frac{28.455 \times 10^{9}}{1.52 \times 10^{6}} \frac{2400^{2}+240^{2}}{2400^{2} \times 240^{2}}} \\
& =0.1451 \frac{1}{1-\eta}=\frac{0.1451}{7.9282 \times 10^{5}}+\frac{1}{(7.7904+7.7904) \times 10^{4}} \\
& J_{\text {eff } ; E E T}=\frac{\eta}{\frac{\eta}{J_{m}}+\frac{1-1451}{J_{\text {glass } 1}+J_{\text {glass } 2}}} \\
& =1.7637 \times 10^{5} \mathrm{~mm}^{4}
\end{aligned}
$$




$$
\begin{aligned}
& G_{E S S M_{-} P V B}=\frac{G J_{\text {eff } ; E E T}}{J_{\text {homog }}}=\frac{28.455 \times 10^{9} \times 1.7637 \times 10^{5}}{7.5224 \times 10^{5}}=6.674 \mathrm{GPa} \\
& \eta=\frac{1}{1+12 \frac{t_{I N T} t_{1} t_{2}}{t_{1}+t_{2}} \frac{J_{\text {glass } 1}+J_{\text {glass } 2}}{J_{m}} \frac{G}{G_{S G P}} \frac{L^{2}+h^{2}}{L^{2} h^{2}}} \\
& =\frac{1}{1+12 \frac{1.52 \times 10^{2}}{10+10} \frac{(7.7904+7.7904) \times 10^{4}}{7.9282 \times 10^{5}} \frac{28.455 \times 10^{9}}{191.03 \times 10^{6}} \frac{2400^{2}+240^{2}}{2400^{2} 240^{2}}} \\
& =0.9553 \quad=\frac{0.9553}{7.9282 \times 10^{5}}+\frac{1}{(7.7904+7.7904) \times 10^{4}} \\
& J_{\text {eff } ; E E T}=\frac{1}{\frac{\eta}{J_{m}}+\frac{1-\eta}{J_{\text {glass } 1}+J_{\text {glass } 2}}} \\
& =6.7032 \times 10^{5} \mathrm{~mm}^{4} \\
& G_{E S S M_{-} S G P}=\frac{G J_{\text {eff } ; E E T}}{J_{\text {homog }}}=\frac{28.46 \times 10^{9} \times 6.7032 \times 10^{5}}{7.5224 \times 10^{5}}=25.354 \mathrm{GPa}
\end{aligned}
$$




\section{References}

[1] Mohamed A, Uheida K, Quan Y, Zhang H. Applicability of the torsion test and photogrammetric approach on structural timber beams. Int Wood Prod J 2021;12:206-17. https://doi.org/10.1080/20426445.2021.1952047.

[2] Pešek O, Melcher J. Lateral-Torsional Buckling of Laminated Structural Glass Beams. Experimental Study. Procedia Eng 2017;190:70-7. https://doi.org/10.1016/j.proeng.2017.05.309.

[3] Bedon C, Belis J, Amadio C. Structural assessment and lateral - torsional buckling design of glass beams restrained by continuous sealant joints. Eng Struct 2015;102:214-29. https://doi.org/10.1016/j.engstruct.2015.08.021.

[4] Bedon C, Belis J, Luible A. Assessment of existing analytical models for the lateral torsional buckling analysis of PVB and SG laminated glass beams via viscoelastic simulations and experiments. Eng Struct 2014;60:52-67. https://doi.org/10.1016/j.engstruct.2013.12.012.

[5] Valarinho L, Correia JR, Machado-e-costa M, Branco FA, Silvestre N. Lateral-torsional buckling behaviour of long-span laminated glass beams : Analytical, experimental and numerical study. Mater Des 2016;102:264-75. https://doi.org/10.1016/j.matdes.2016.04.016.

[6] Belis J, Bedon C, Louter C, Amadio C, Impe R Van. Experimental and analytical assessment of lateral torsional buckling of laminated glass beams. Eng Struct 2013;51:295-305. https://doi.org/10.1016/j.engstruct.2013.02.002.

[7] Luible A, Schärer D. Lateral torsional buckling of glass beams with continuous lateral support. Glas Struct Eng 2016;1:153-71. https://doi.org/10.1007/s40940-016-0008-3.

[8] Galuppi L, Royer-Carfagni G. Enhanced Effective Thickness for laminated glass beams and plates under torsion. Eng Struct 2020;206:110077. https://doi.org/10.1016/j.engstruct.2019.110077.

[9] Luible A, Crisinel M. Design of Glass Beams Subjected to Lateral Torsional Buckling. IABSE Symp Rep 2006;92:45-52. https://doi.org/10.2749/222137806796168903.

[10] Amadio C, Bedon C. Buckling of laminated glass elements in out-of-plane bending. Eng Struct 2010;32:3780-8. https://doi.org/https://doi.org/10.1016/j.engstruct.2010.08.022.

[11] Feldmann M, Kasper R. Guidance for European Structural Design of Glass Components. Luxembourg: JRC Scientific and Policy Reports; 2014. https://doi.org/10.2788/5523.

[12] Schuler C, Bucak Ö, Albrecht G, Sackmann V, Gräf H. Time and Temperature Dependent Mechanical Behaviour and Durability of Laminated Safety Glass. Struct Eng Int 2004;14:80-3.

https://doi.org/10.2749/101686604777964026.

[13] Galuppi L, Royer-Carfagni G. Laminated beams with viscoelastic interlayer. Int J Solids Struct 2012;49:2637-45. https://doi.org/https://doi.org/10.1016/j.ijsolstr.2012.05.028.

[14] Minahen TM, Knauss WG. Creep buckling of viscoelastic structures. Int J Solids Struct 1993;30:1075-92. https://doi.org/https://doi.org/10.1016/0020-7683(93)90004-Q.

[15] Galuppi L, Royer-Carfagni G. Buckling of three-layered composite beams with viscoelastic interaction. Compos Struct 2014;107:512-21. https://doi.org/https://doi.org/10.1016/j.compstruct.2013.08.006.

[16] Musgraves JD, Hu J, Calvez L. Springer Handbook of Glass. Cham: Springer; 2019.

[17] Gaafar MS, Afifi HA, Mekawy MM. Structural studies of some phospho-borate glasses using ultrasonic pulse-echo technique, DSC and IR spectroscopy. Phys B Condens Matter 2009;404:1668-73. https://doi.org/10.1016/j.physb.2009.01.045.

[18] ASTM. ASTM C623 - 92(2015): Standard Test Method for Young's Modulus, Shear Modulus, and Poisson's Ratio for Glass and Glass-Ceramics by Resonance 2015.

[19] British Standards Institution BSI. BS EN 408:2010+A1:2012: Timber structures. Structural timber and glued laminated timber. Determination of some physical and mechanical properties 2010.

[20] Mohamed AS. Photogrammetric and Stereo Vision Techniques for Evaluating Material Properties in Timber and Timber-Based Composite Structures. Edinburgh Napier University, 2016. 
[21] Gharavi N, Zhang H, Xie Y, He T. End effect on determining shear modulus of timber beams in torsion tests. Constr Build Mater 2018;164. https://doi.org/10.1016/j.conbuildmat.2017.12.191.

[22] Granshaw S 1. Laussedat Bicentenary: Origins of Photogrammetry. Photogramm Rec 2019;34:128-47. https://doi.org/10.1111/phor.12277.

[23] Peters WH, Ranson WF. Digital imaging techniques in experimental stress analysis. Opt Eng 1982;21:427-31.

[24] Sutton M, Wolters W, Peters W, Ranson W, McNeill S. Determination of displacements using an improved digital correlation method. Image Vis Comput 1983;1:133-9. https://doi.org/10.1016/0262-8856(83)90064-1.

[25] Gharavi N, Zhang H. Study on the Impact of Size and Position of the Shear Field in Determining the Shear Modulus of Glulam Beam Using Photogrammetry Approach. Int J Struct Constr Eng 2018;12:218-22.

[26] Mohamed A, Deng Y, Zhang H, Wong SHF, Uheida K, Zhang YX, et al. Photogrammetric Evaluation of Shear Modulus of Glulam Timber Using Torsion Test Method and Dual Stereo Vision System. Eur J Wood Wood Prod 2021;79:1209-1223. https://doi.org/10.1007/s00107-021-01729-8.

[27] Zhang H, Mohamed A, Xiao Z. Evaluation of the shear constant of a timber beam using a photogrammetric approach. Proc. 13th Int. Conf. Civil, Struct. Environ. Eng. Comput., 2011.

[28] Mohamed A, Zhang H, Smith I, Xiao Z. A low cost non-contact and non-destructive method for evaluating the variation of the shear modulus for glued laminated timber beams using a photogrammetric approach. Civil-Comp Proc 2015;108.

[29] Zhang H, Gharavi N, Wong SH, Deng Y, Bahadori-Jahromi A, Limkatanyu S, et al. Effect of concentrated ButtJoints on flexural properties of laminated Bamboo-Timber flitch beams. J Sandw Struct Mater 2021:109963622110401. https://doi.org/10.1177/10996362211040103.

[30] Veer FA, Bristogianni T, Baardolf G. A case study of apparently spontaneous fracture. Glas Struct Eng 2017. https://doi.org/10.1007/s40940-017-0047-4.

[31] O’Regan C. Structural use of glass in buildings. 2nd ed. London: Institution of Structural Engineers; 2015.

[32] Steger C, Ulrich M, Wiedemann C. Machine Vision Algorithms and Applications. 2nd ed. Weinheim: Wiley-VCH; 2017.

[33] MVTec. HALCON/HDevelop Operator Reference. Munich: 2018.

[34] Boresi AP, Schmidt RJ. Advanced Mechanics of Materials. 6th ed. Hoboken, NJ: John Wiley \& Sons Inc; 2003.

[35] Timoshenko S, Goodier JN. Theory of Elasticity, 3rd edMcGraw-Hill. New York 1970.

[36] Kasper R, Sedlacek G, Feldmann M. Das Biegedrillknickverhalten von Glasträgern aus Verbundglas. Stahlbau 2007;76:167-76. https://doi.org/https://doi.org/10.1002/stab.200710020.

[37] Kuraray. Physical Properties of SentryGlas and Butacite 2014.

[38] British Standards Institution BSI. BS EN 572-1-2012+A1-2016 Glass in building - Basic soda lime silicate glass products - Part 1: Definitions and general physical and mechanical properties. London: 2017.

[39] British Standards Institution BSI. BS EN 16612:2019 BGlass in building - Determination of the lateral load resistance of glass panes by calculation 2019.

[40] DuPont. PVB Properties: tempeature and load duration n.d.

[41] DuPont. SentryGlas Plus Elastic Properties (SGP 5000) n.d. 
Table 1: Test Samples $(*=$ toughened, $* *=$ heat soaked)

\begin{tabular}{ccccccc}
\hline ABBREV & $\begin{array}{c}\text { Length } \\
(\mathrm{mm})\end{array}$ & $\begin{array}{c}\text { Height } \\
(\mathrm{mm})\end{array}$ & $\begin{array}{c}\text { Thickness } \\
(\mathrm{mm})\end{array}$ & $\begin{array}{c}\text { Glass } \\
\text { Type }\end{array}$ & $\begin{array}{c}\text { No. Glass } \\
\text { Plys }\end{array}$ & $\begin{array}{c}\text { Composition } \\
(\mathrm{mm})\end{array}$ \\
\hline MONO1 & 2400 & 240 & 10 & $\mathrm{~T}^{*}, \mathrm{HS}^{* *}$ & 1 & 10 \\
2PVB1 & 2400 & 240 & 21.52 & $\mathrm{~T}^{*}, \mathrm{HS}^{* *}$ & 2 & $10|1.52| 10$ \\
2SGP1 & 2400 & 240 & 21.52 & $\mathrm{~T}^{*}, \mathrm{HS}^{* *}$ & 2 & $10|1.52| 10$ \\
\hline
\end{tabular}

Table 2: Material properties of soda-lime silica glass $(*$ bending strength from basic annealed to thermallytoughened) $[31,38,39]$

\begin{tabular}{cc}
\hline Material Property & Value \\
\hline Characteristic bending strength* $f_{g ; k}$ & $45 \mathrm{~N} / \mathrm{mm}^{2}$ to $120 \mathrm{~N} / \mathrm{mm}^{2}$ \\
Density $\rho$ & $2500 \mathrm{~kg} / \mathrm{m}^{3}$ \\
Young's modulus $E$ & $70,000 \mathrm{~N} / \mathrm{mm}^{2}$ \\
Shear modulus $G$ & $28,700 \mathrm{~N} / \mathrm{mm}^{2}$ \\
Poisson's ratio $\boldsymbol{\mu}$ & $0.23[39]$ \\
\hline
\end{tabular}

Table 3: Results of photogrammetry accuracy validation

\begin{tabular}{ccc}
\hline Micrometre measurement $(\mathrm{mm})$ & Photogrammetry method $(\mathrm{mm})$ & Error $(\%)$ \\
& & \\
\hline-3.181 & -3.173 & 0.26 \\
-5.710 & -5.712 & 0.03 \\
-8.894 & -8.924 & 0.33 \\
-10.179 & -10.155 & 0.24 \\
\hline
\end{tabular}

Table 4: PVB Shear Modulus under various load duration [40]

\begin{tabular}{cccccc}
\hline$G_{P V B}(\mathrm{MPa})$ & $\mathbf{3 s}$ & $\mathbf{1}$ min, & 1 hour & 1 day & 1 month \\
\hline $\mathbf{2 0}{ }^{\circ} \mathrm{C}$ & 8.06 & 1.64 & 0.84 & 0.508 & 0.372 \\
\hline
\end{tabular}

Table 5: SGP Shear Modulus under various load duration [41]

\begin{tabular}{cccccc}
\hline$G_{S G P}(\mathrm{MPa})$ & 3s & 1 min, & 1 hour & 1 day & 1 month \\
\hline $20^{\circ} \mathrm{C}$ & 211 & 195 & 169 & 146 & 112 \\
\hline
\end{tabular}




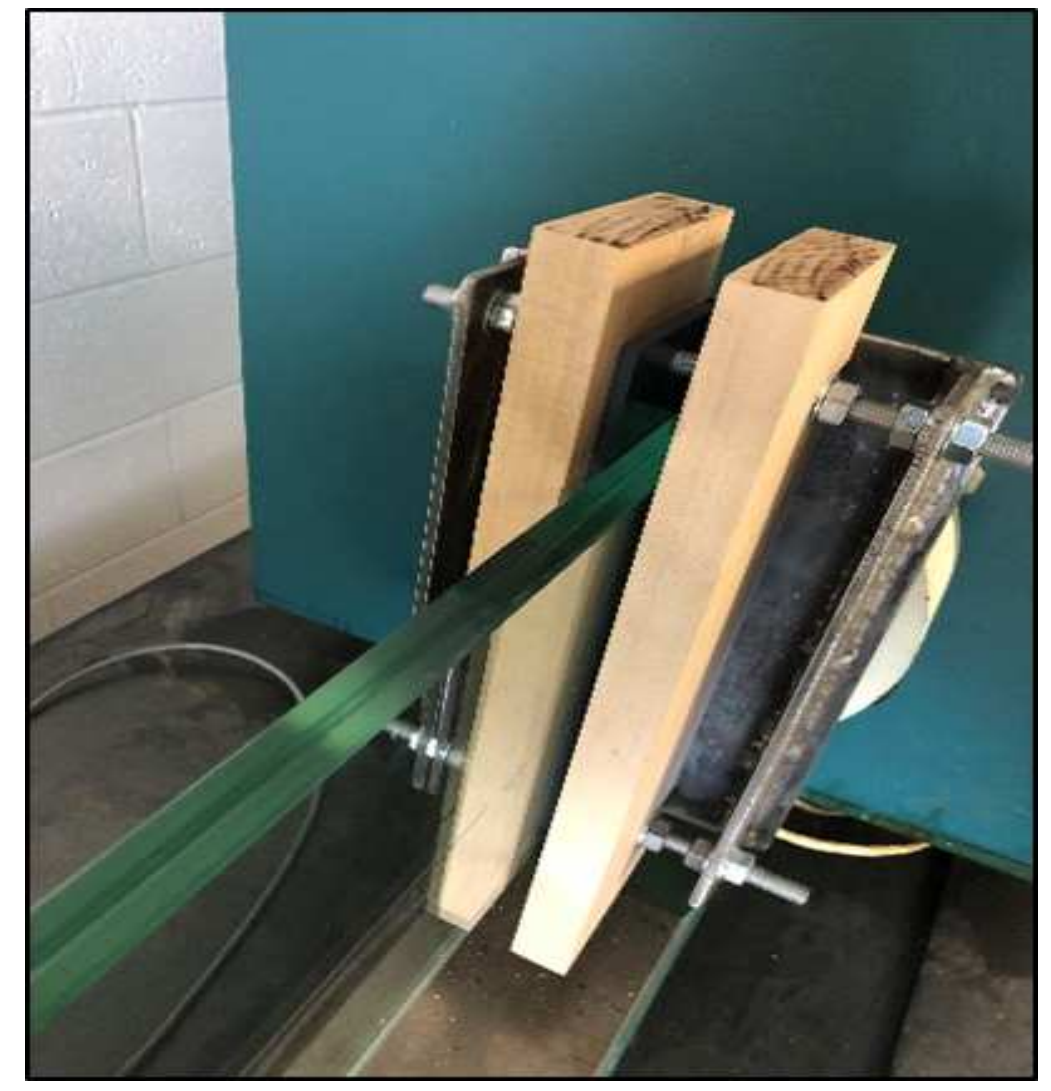

Fig. 1. Clamp and inserts

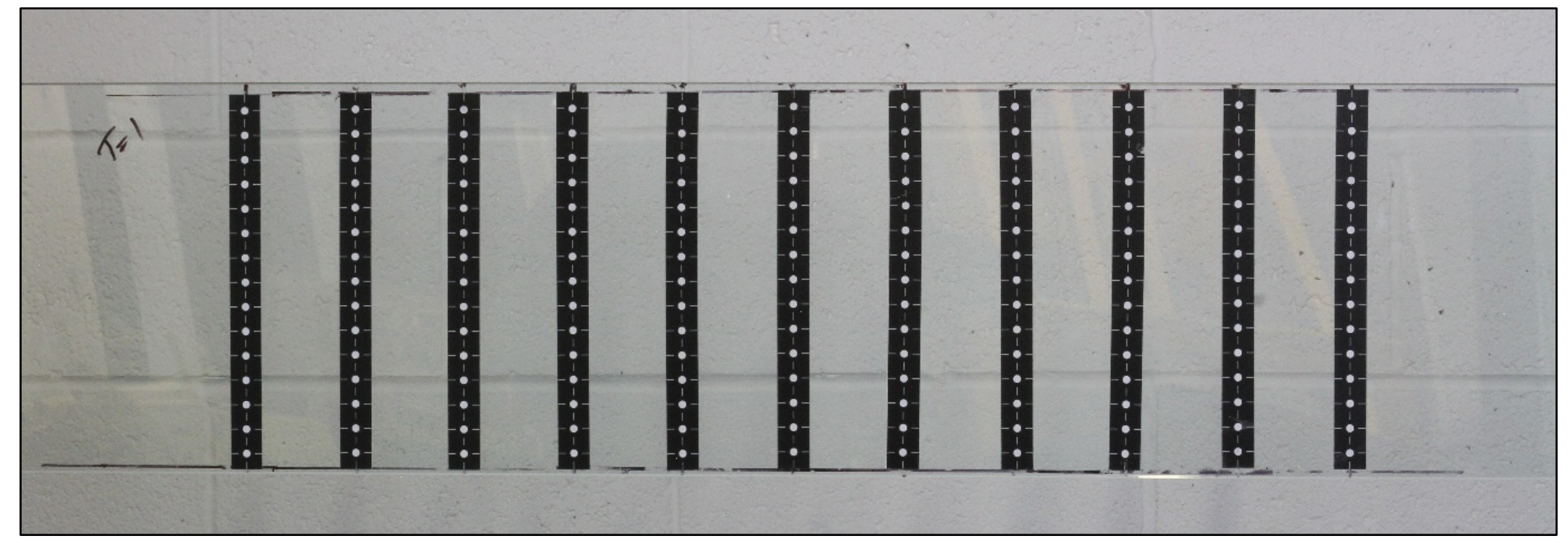

Fig. 2. Beam target setup 


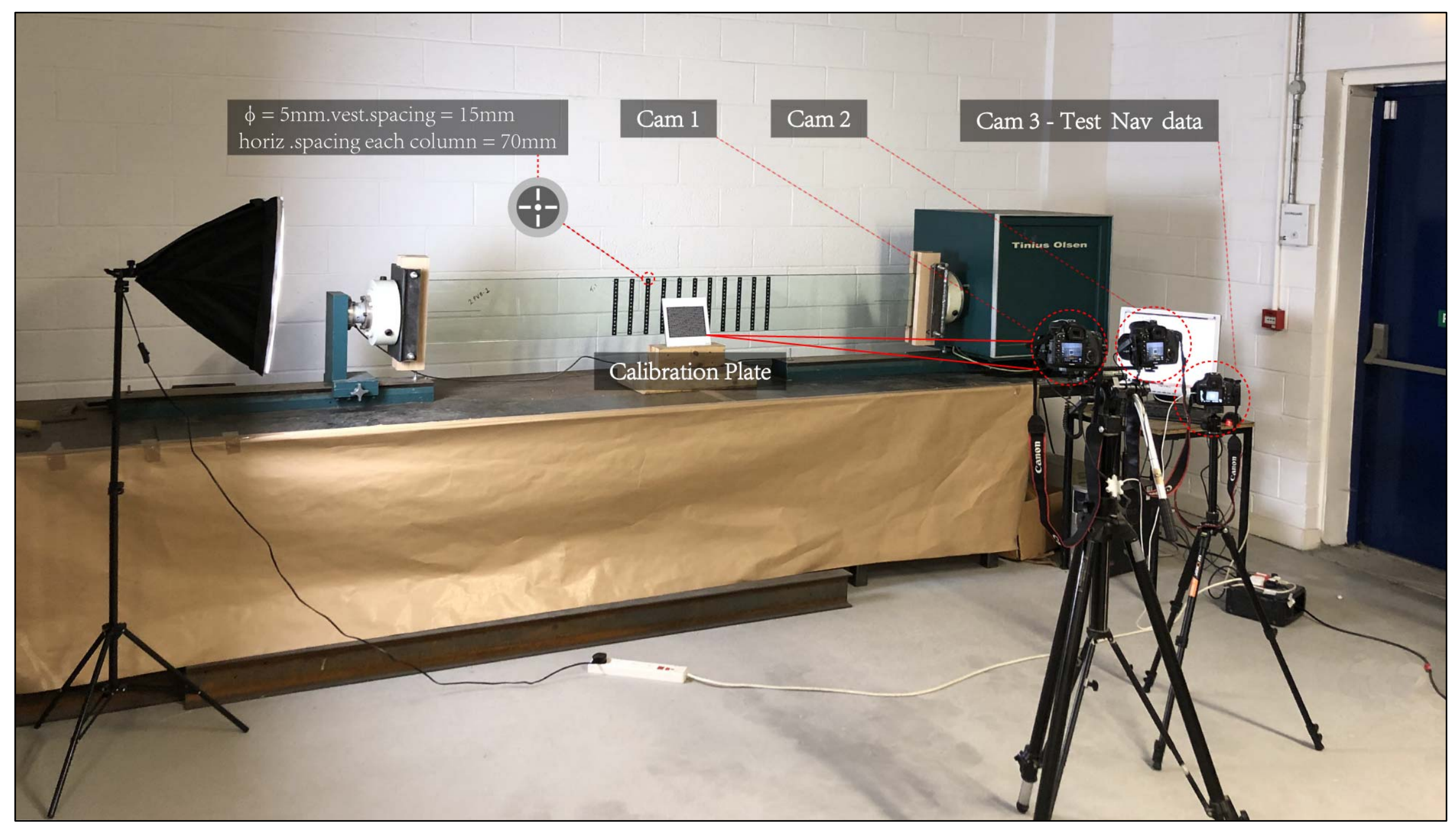

Fig. 3. Test setup 


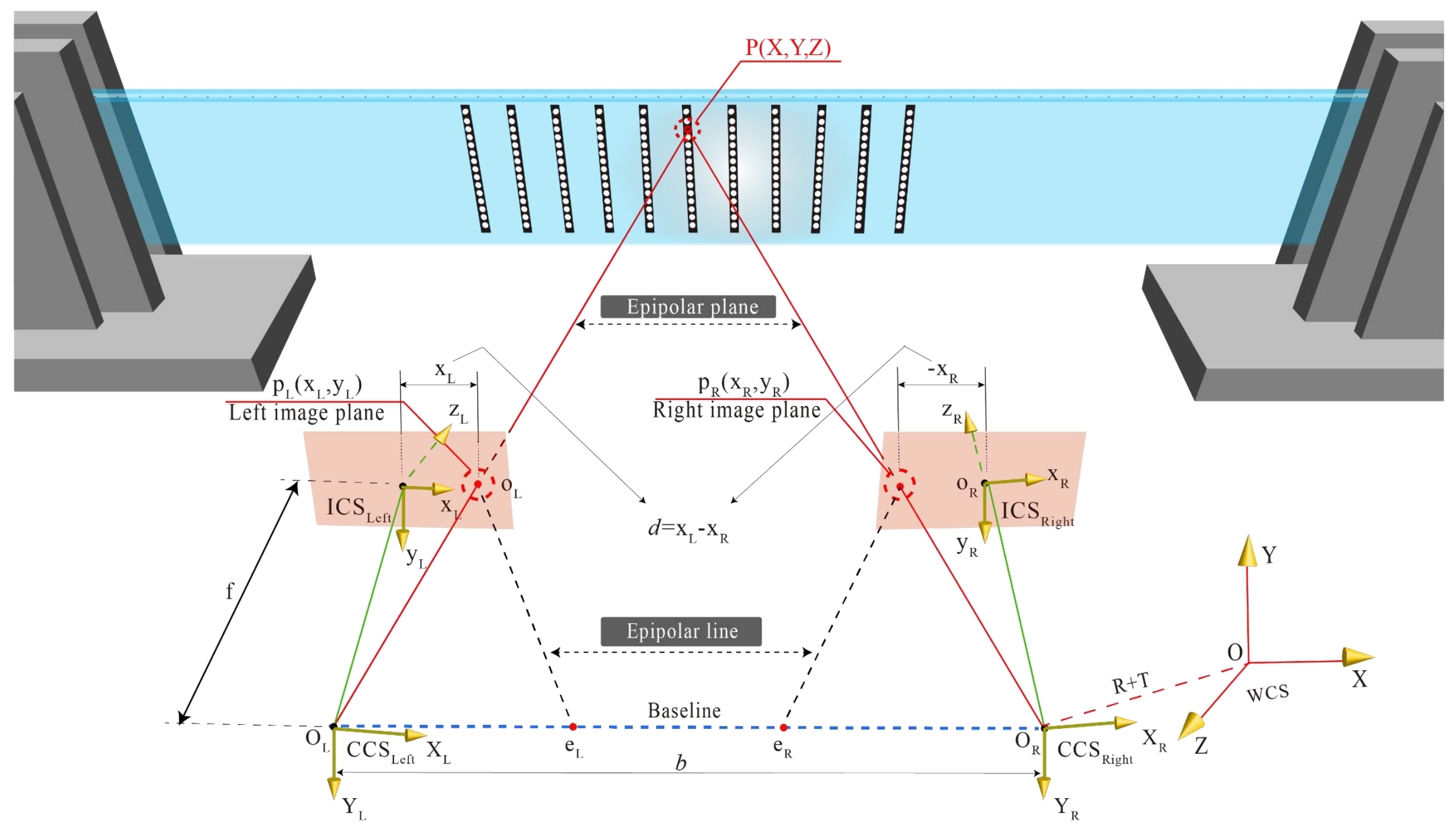

Fig. 4. Binocular stereo-vision principle depicting a beam target as object point $P$ 


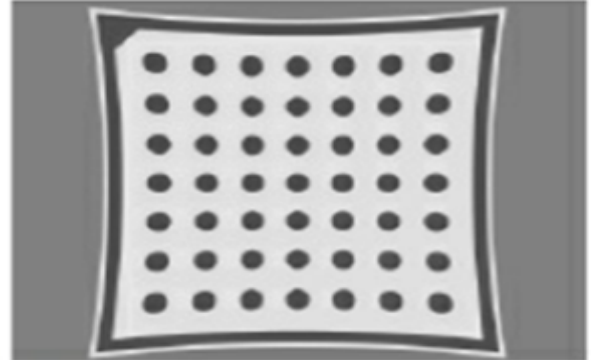

(a)

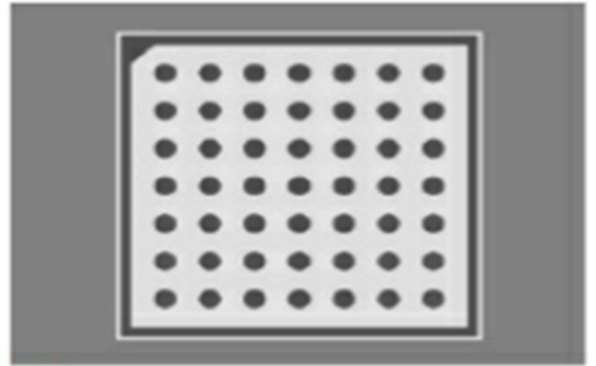

(b)

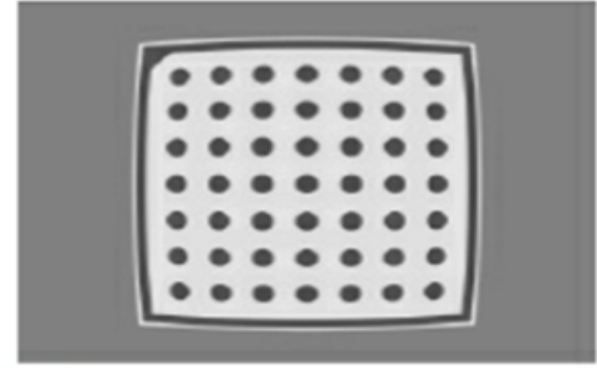

(c)

Fig. 5. Lens distortion effects - (a) pincushion distortion, (b) no distortion, (c) barrel distortion [32] 


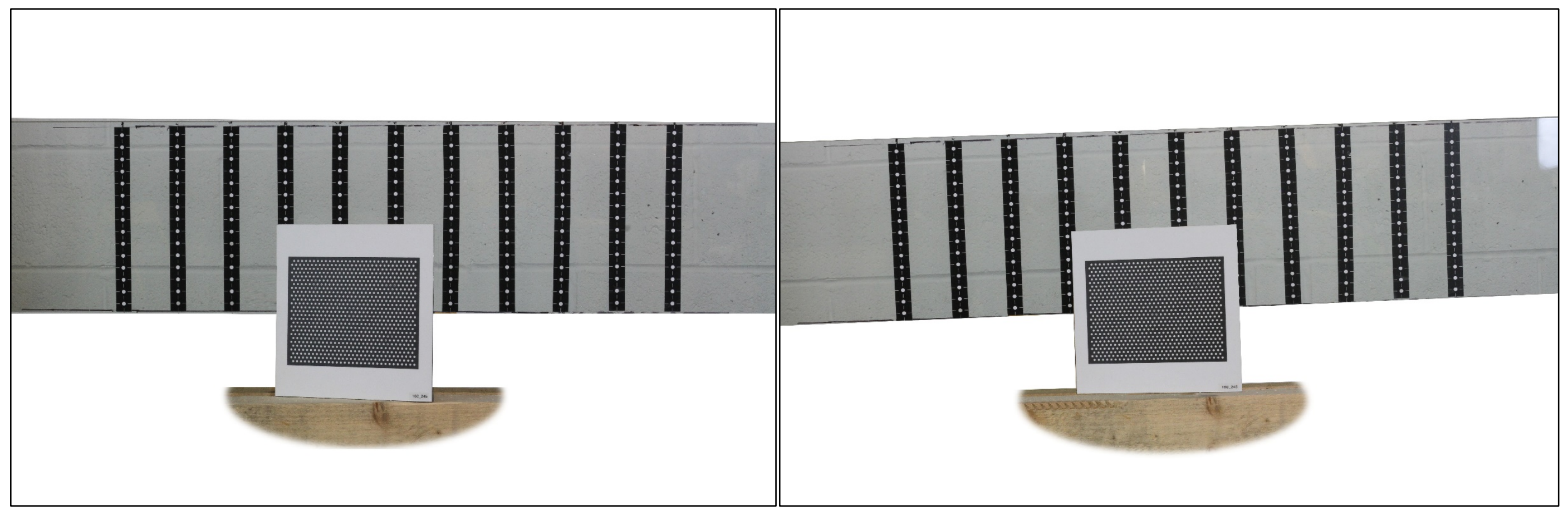

Fig. 6. Calibration image pair taken by left and right cameras, respectively 


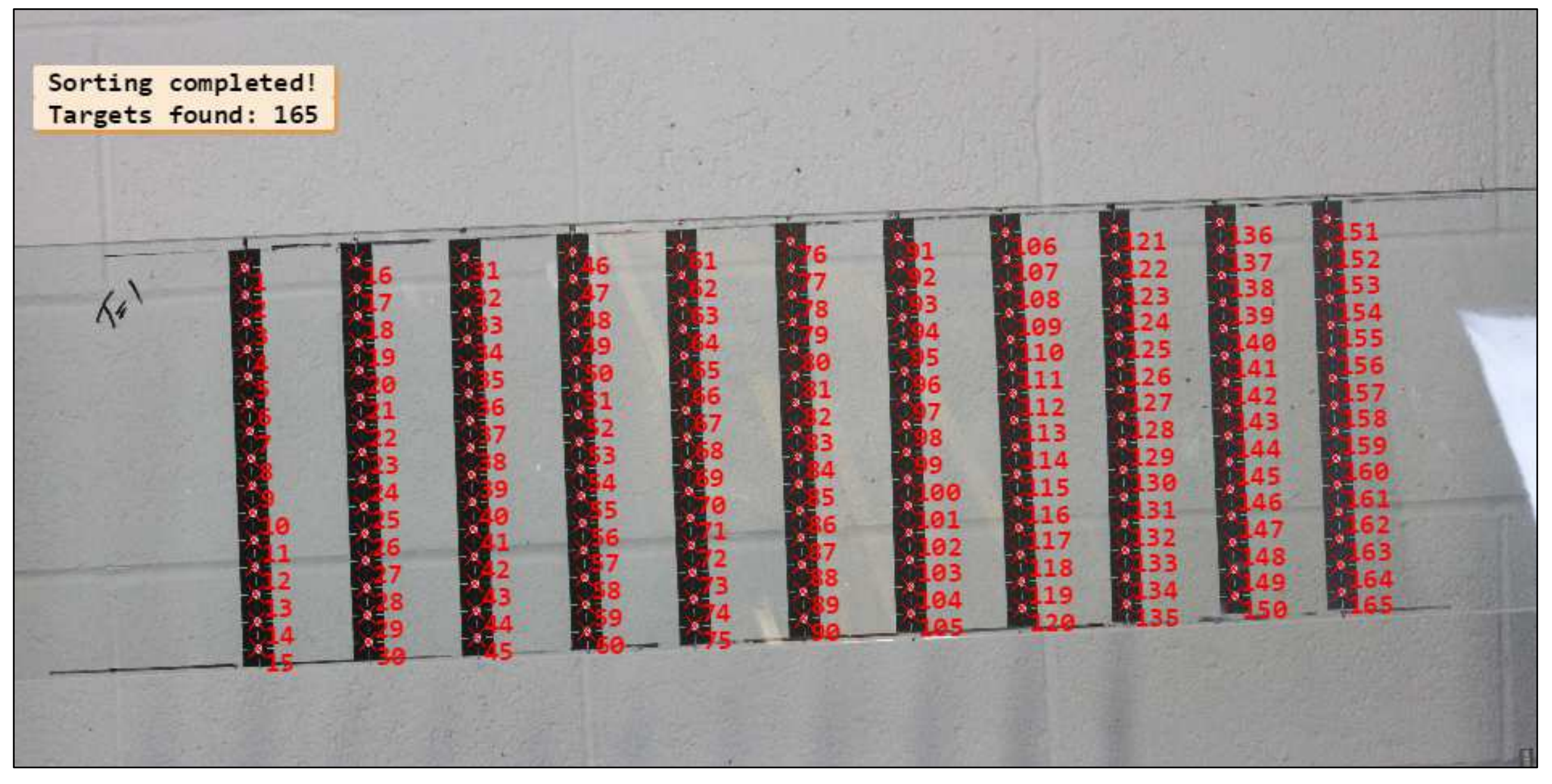

Fig. 7. Extracted targets and centres 


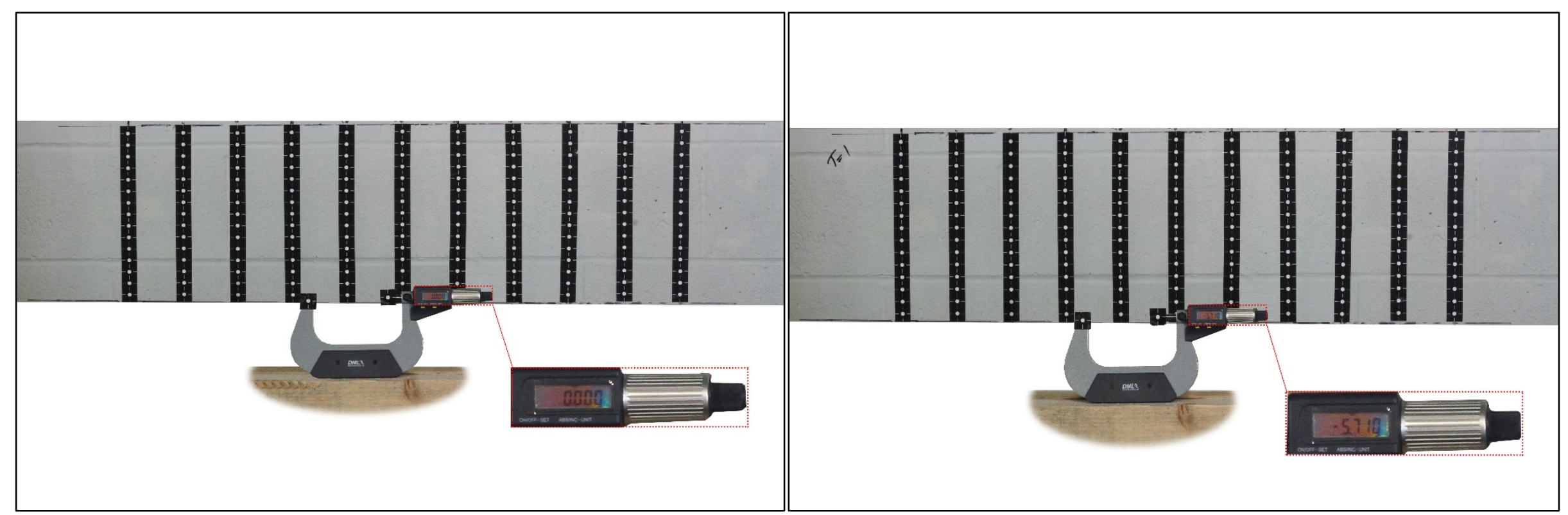

Fig. 8. Micrometre test at zero (left) and interval (right) 


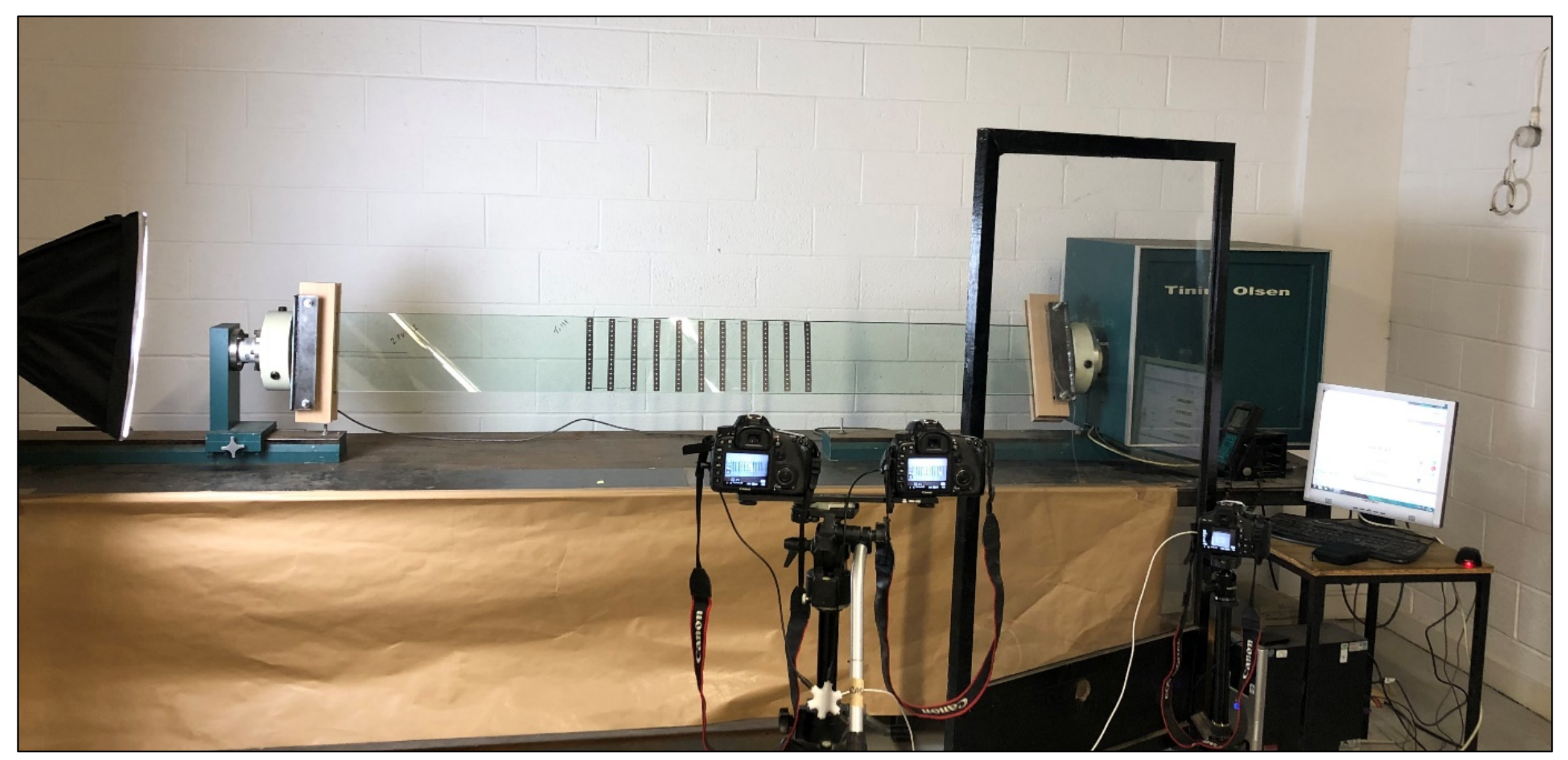

Fig. 9. Active torsion test 


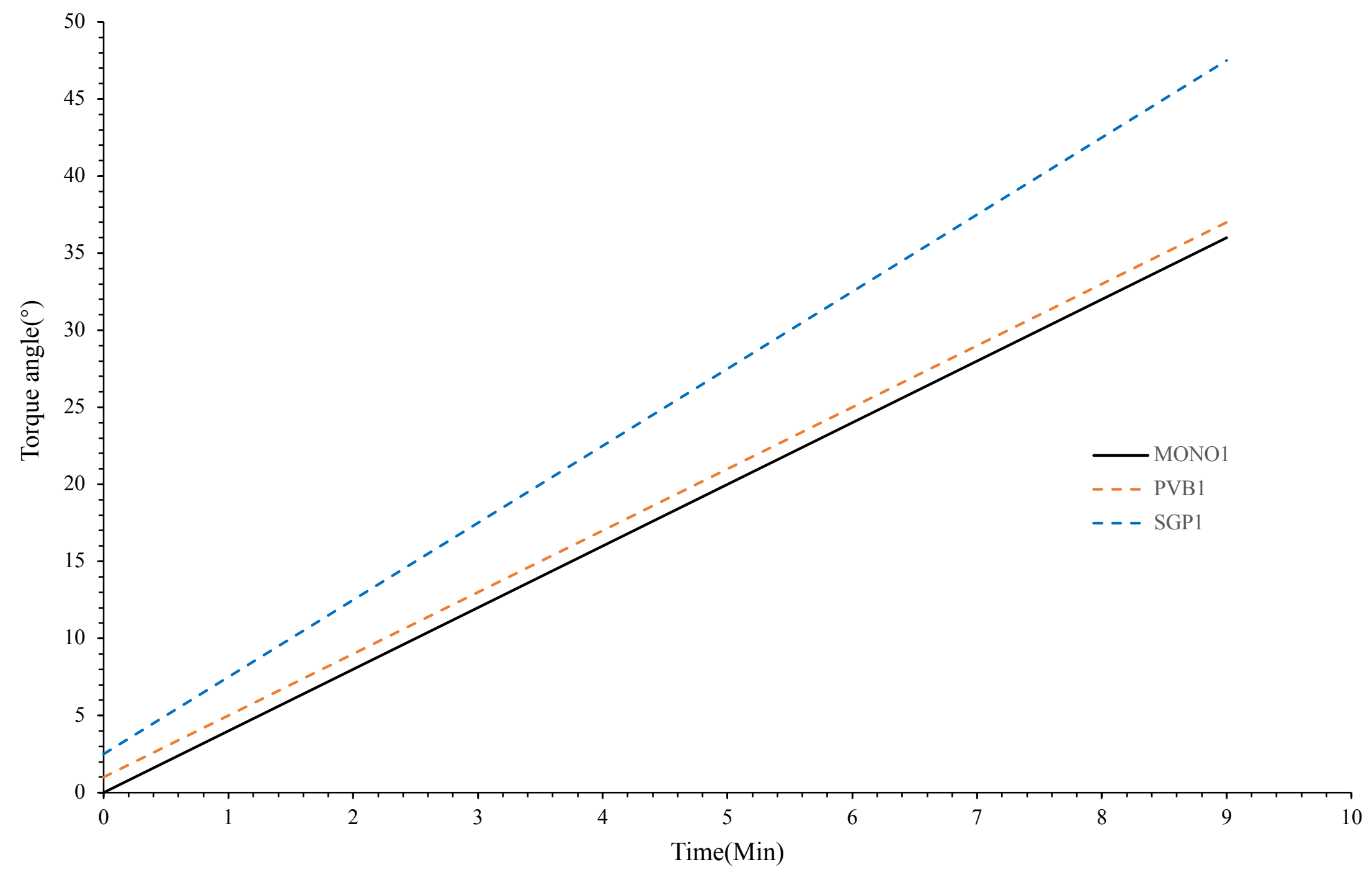

Fig. 10. Torque-time relationship 


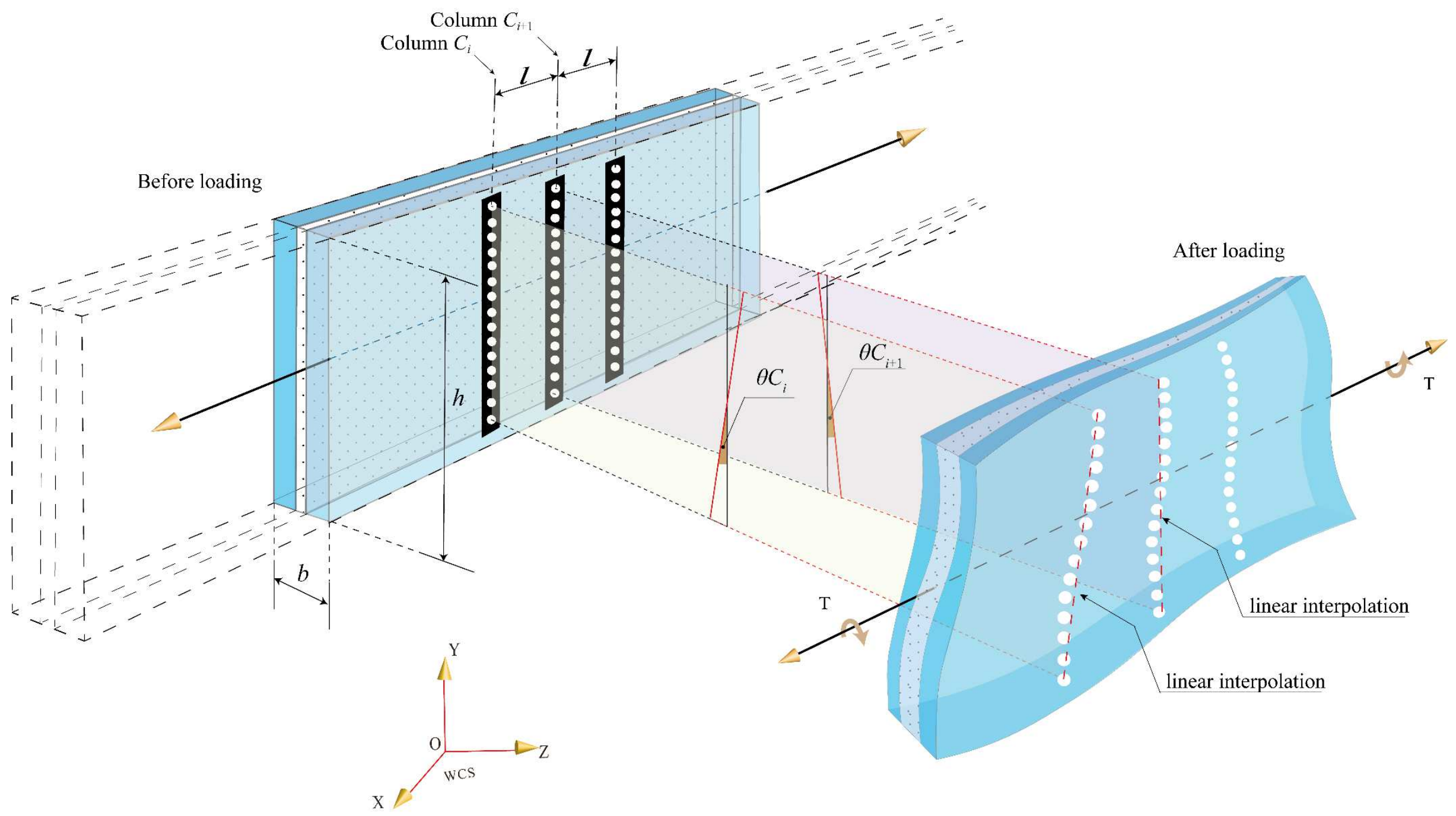

Fig. 11. Double-ply laminated glass beam with target columns before and after torsion 
Calibration process completed.

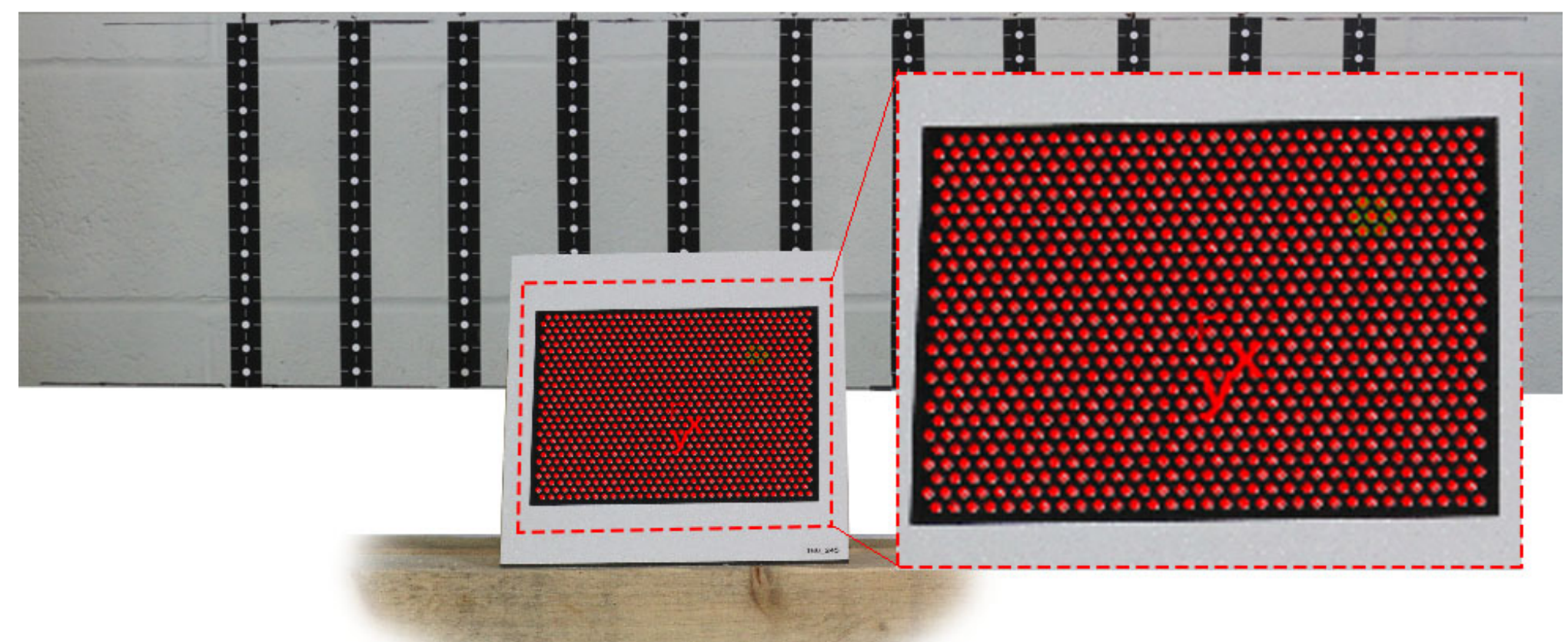

Press Run (F5) to continue

Fig. 12. Calibration in HALCON software 


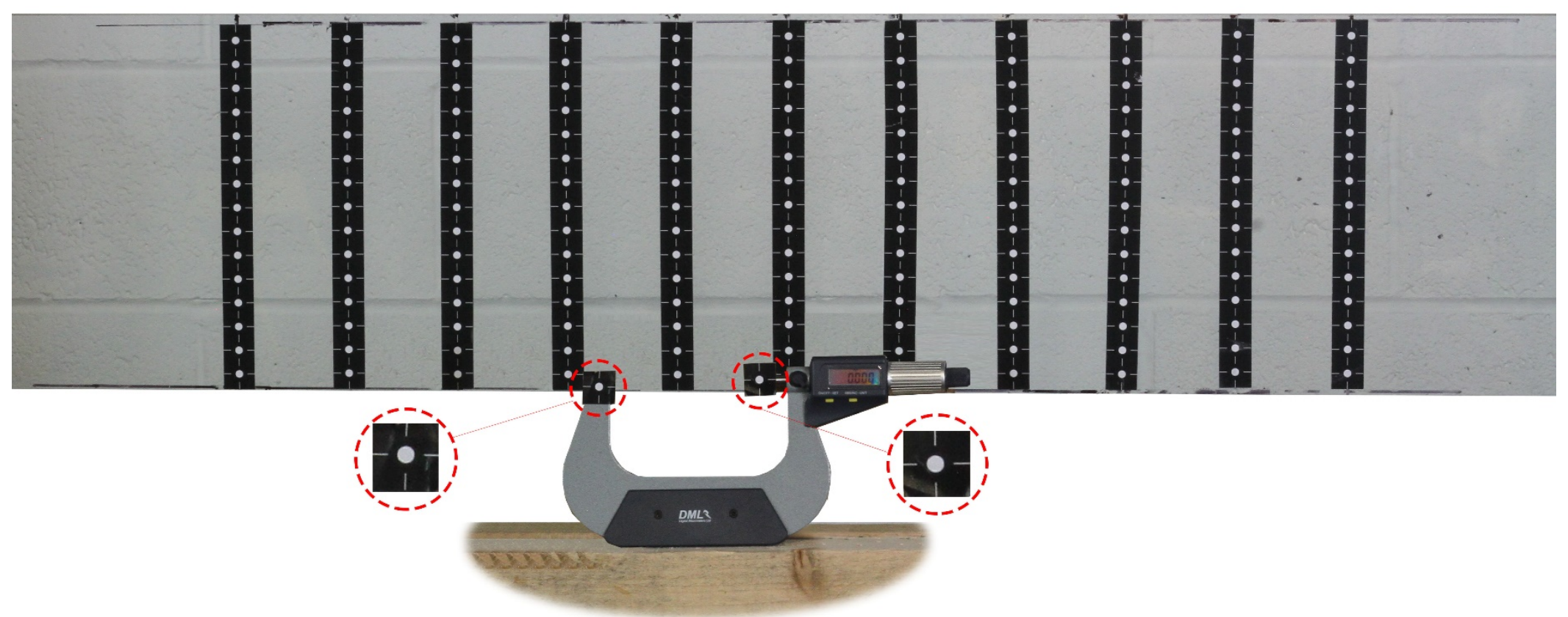

Fig. 13. Recognition of micrometre targets 


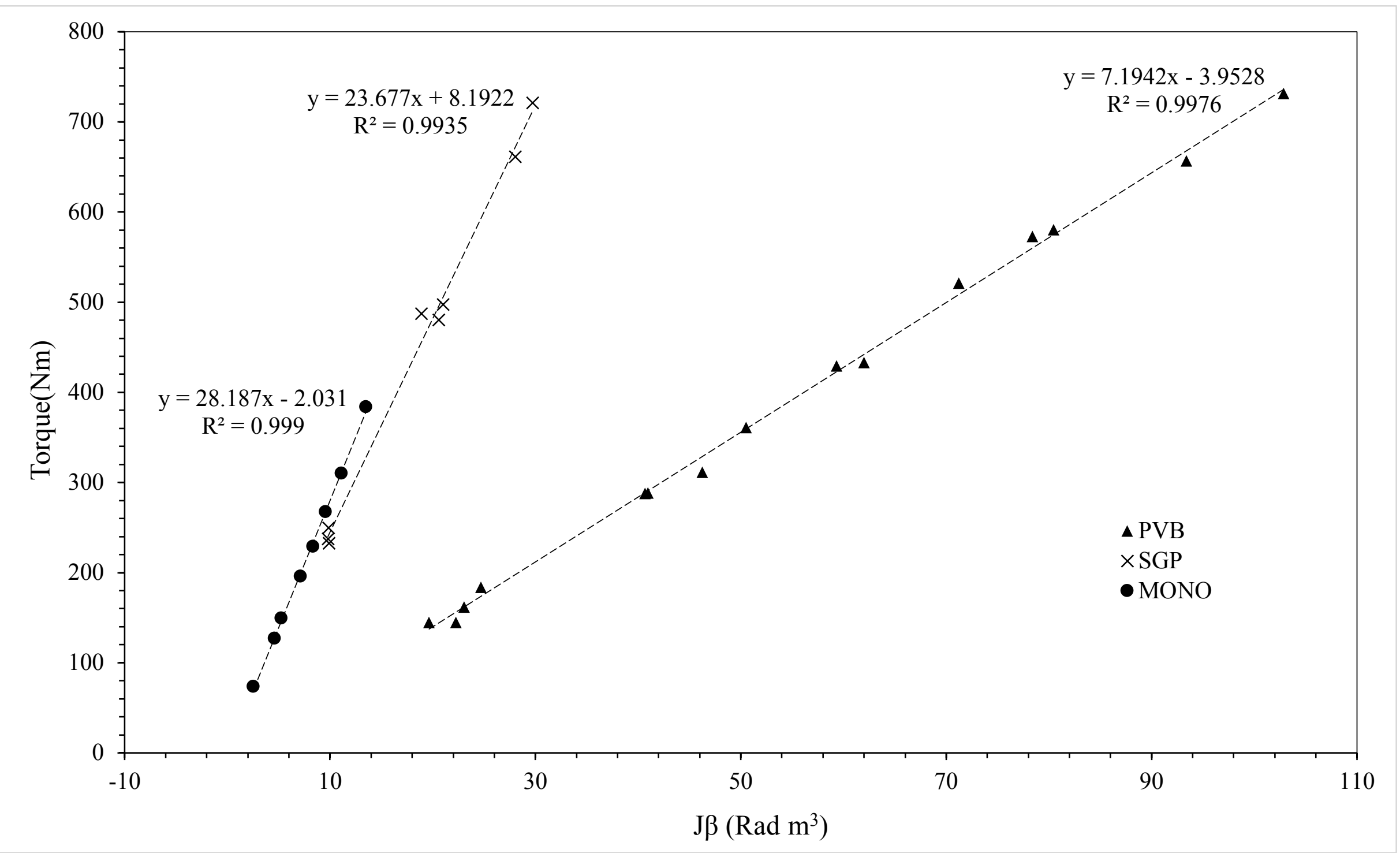

Fig. 14. Shear modulus evaluation for monolithic and laminated glass beam 